\title{
Altered immune cell follicular dynamics in HIV infection following influenza vaccination
}

\author{
Eirini Moysi, ${ }^{1,2}$ Suresh Pallikkuth, ${ }^{2}$ Lesley R. De Armas, ${ }^{2}$ Louis E. Gonzalez, ${ }^{2}$ David Ambrozak, ${ }^{3}$ Varghese George, ${ }^{2}$ \\ David Huddleston, ${ }^{4}$ Rajendra Pahwa, ${ }^{2}$ Richard A. Koup, ${ }^{3}$ Constantinos Petrovas, ${ }^{1}$ and Savita Pahwa ${ }^{2}$ \\ 'Tissue Analysis Core, Immunology Laboratory, Vaccine Research Center (VRC), National Institute of Allergy and Infectious Diseases (NIAID), NIH, Bethesda, Maryland, USA. ²Department of Microbiology \\ and Immunology, University of Miami Miller School of Medicine, Miami, Florida, USA. ${ }^{3}$ Immunology Laboratory, VRC, NIAID, NIH, Bethesda, Maryland, USA. ${ }^{4}$ Department of Trauma Surgery, \\ University of Miami Miller School of Medicine, Miami, Florida, USA.
}

\begin{abstract}
HIV infection changes the lymph node (LN) tissue architecture, potentially impairing the immunologic response to antigenic challenge. The tissue-resident immune cell dynamics in virologically suppressed HIV $^{+}$patients on combination antiretroviral therapy (cART) are not clear. We obtained LN biopsies before and 10 to 14 days after trivalent seasonal influenza immunization from healthy controls (HCs) and $\mathrm{HIV}^{+}$volunteers on cART to investigate $\mathrm{CD}^{+}{ }^{+}$follicular helper (Tfh) and B cell dynamics by flow cytometry and quantitative imaging analysis. Prior to vaccination, compared with those in HCs, HIV+ LNs exhibited an altered follicular architecture, but harbored higher numbers of Tfh cells and increased IgG+ follicular memory B cells. Moreover, Tfh cell numbers were dependent upon preservation of the follicular dendritic cell (FDC) network and were predictive of the magnitude of the vaccine-induced IgC responses. Interestingly, postvaccination LN samples in HIV+ participants had significantly $(P=0.0179)$ reduced Tfh cell numbers compared with prevaccination samples, without evidence for peripheral Tfh (pTfh) cell reduction. We conclude that influenza vaccination alters the cellularity of draining LNs of HIV ${ }^{+}$ persons in conjunction with development of antigen-specific humoral responses. The underlying mechanism of Tfh cell decline warrants further investigation, as it could bear implications for the rational design of HIV vaccines.
\end{abstract}

\section{Introduction}

The introduction of combination antiretroviral therapy (cART) for the treatment of HIV infection has dramatically altered the course of HIV/AIDS, prolonging life span to nearly normal and minimizing the risk for opportunistic infections (1). Despite immune restoration of $\mathrm{CD}^{+} \mathrm{T}$ cells and improved immune profile with treatment, HIV-infected individuals remain at a higher risk for influenza infections compared with healthy individuals (2) and it is recommended that they receive seasonal influenza vaccinations on a yearly basis (3).

It is well established that lymph node (LN) structure and cellularity are significantly altered in $\operatorname{HIV}(4,5)$ and may not achieve normality $(6,7)$. We and several groups have shown that the ability of HIV-infected individuals to mount adequate antibody responses to immunization may be compromised (8-13). However, the relevant LN immune dynamics in the context of HIV and cART remain unknown. T follicular helper ( $\mathrm{Tfh}$ ) cells are a highly specialized subset of $\mathrm{CD}^{+} \mathrm{T}$ cells that localize within the follicles and, more specifically, germinal centers (GC-Tfh) $(14,15)$. Although the exact ontogeny of these cells remains controversial, several lines of evidence have established their role in B cell maturation, recombination, class switching, and antibody production (16-19) that occur via specific receptor-ligand interactions and cytokine production

Authorship note: CP and SP contributed equally to this work. Conflict of interest: The authors have declared that no conflict of interest exists. Submitted: January 18, 2018; Accepted: April 25, 2018

Reference information: J Clin Invest. 2018;128(7):3171-3185.

https://doi.org/10.1172/JCI99884.
$(20,21)$. HIV and SIV infection result in accumulation of Tfh cells in LNs; these cells have been found to be highly permissive for HIV, which contributes to HIV persistence (22-24). Furthermore, significant changes of the Tfh cell gene signature (24) in LN and in the circulating peripheral counterparts of Tfh (pTfh) have been described in HIV infection $(25,26)$. Given the heightened risk of HIV seropositive individuals for comorbid diseases and the need for less toxic treatment alternatives for long-term disease management, understanding tissue-specific immunity becomes increasingly important. We used seasonal influenza vaccination to study Tfh and B cell dynamics at lymphoid tissue levels in the context of ART-controlled chronic HIV infection. We show that LNs from $\mathrm{HIV}^{+}$individuals on cART are enriched for Tfh cells compared with LNs from healthy participants before vaccination and that Tfh cells are preferentially localized in follicles that maintain the FDC network architecture. In addition, the examination of Tfh cell frequencies in the context of response to vaccination revealed that prevaccination frequencies could predict the serologic response to the less frequently encountered influenza B antigen in our cohort. We further show that vaccination also induced a global reduction in the frequencies of Tfh cells in the LNs of $\mathrm{HIV}^{+}$participants.

\section{Results}

LNs of $\mathrm{HIV}^{+}$patients on cART have higher frequencies of $\mathrm{Tfh} \mathrm{CD}^{+} \mathrm{T}$ cells than those of healthy controls before vaccination. The dynamics of Tfh cells in patients chronically infected with HIV who remain on cART is not well understood. We took advantage of a number of paired and unpaired draining inguinal LN biopsies obtained from healthy controls ( $\mathrm{HCs}$ ) and $\mathrm{HIV}^{+}$individuals before and after 
Table 1. Demographic characteristics of the study participants before vaccination

$\begin{array}{lcc} & \text { HIV }^{+} \text {cART } & \text { HC } \\ \text { Participants, } n & 15 & 5 \\ \text { Sex (male/female) } & 7 / 8 & 5 / 0 \\ \text { Before and after vaccine pairs } & 6 & 4 \\ \text { Age, yr, median (range) } & 50(35-57) & 52(30-57) \\ \text { Duration of ART, yr, mean }( \pm \text { SD) } & 3.6( \pm 0.6) & \text { NA } \\ \text { Lymphocytes, cells } / \mu \text { mean }( \pm S D) & 2089( \pm 508.9) & 2268.4( \pm 555.8) \\ \text { CD4, cells } / \mu \text { l, mean }( \pm S D) & 711( \pm 239.6) & 906.6( \pm 247) \\ \text { CD8, cells } / \mu l \text {, mean }( \pm S D) & 547( \pm 241.5) & 570( \pm 319) \\ \text { CD4/CD8 ratio, mean }( \pm S D) & 1.6( \pm 1.2) & 1.6( \pm 0.7)\end{array}$

influenza vaccination (as summarized in Table 1) to investigate the impact of chronic HIV infection and cART upon the dynamics of subsequent $\mathrm{CD} 4^{+} \mathrm{T}$ cell mobilization. As shown in Figure $1 \mathrm{~A}$, we began the analysis at study entry by measuring the relative frequencies (\%) of Tfh cells in draining inguinal LNs using a polychromatic flow cytometry assay using LN mononuclear cell (LNMC) suspension. The gating strategy adopted is shown in Figure 1B. Tfh $\mathrm{CD}^{+} \mathrm{T}$ cells were defined based on their high expression of PD-1 and CXCR5, both of which are classic markers of Tfh cells (27). In addition, we dissected the Tfh cell population based on the expression of the marker CD57. CD57 is a glycoprotein expressed on a subset of GC CD4 ${ }^{+} \mathrm{T}$ cells that has been associated with an increased potential for GC B cell help (28). Our analysis revealed a statistically significant enrichment of Tfh cells in the LN cell suspensions of $\mathrm{HIV}^{+}$individuals compared with $\mathrm{HCs}(1.4 \% \pm$ $0.6 \%$ versus $0.6 \% \pm 0.4 \%, P=0.0272$ ) (Figure $1 \mathrm{C}$ ), which is in line with previously described data (22). The frequency of $\mathrm{CD} 57^{+}$and CD57- Tfh cells was also higher in $\mathrm{HIV}^{+}$individuals compared with $\mathrm{HCs}$, with the difference being statistically significant for $\mathrm{CD} 57^{+}$ Tfh cells (Figure 1C). We further investigated the expression of ICOS, CD150 (SLAM), and CXCR3 on Tfh cells, surface receptors linked to Tfh function, and antigen-specific B cell response development in the context of immunization $(24,29-32)$. An increased frequency of Tfh cells expressing ICOS and SLAM (ICOS ${ }^{\text {hiSLAM }}{ }^{\text {hi }}$ ) was found in $\mathrm{HIV}^{+}$individuals compared with $\mathrm{HCs}$ (Supplemental Figure 1, A and C; supplemental material available online with this article; https://doi.org/10.1172/JCI99884DS1). Interestingly the expression level per cell (determined by mean fluorescence intensity [MFI]) of SLAM was higher on Tfh cells from $\mathrm{HIV}^{+}$individuals compared with HCs (Supplemental Figure 1B). Similarly, frequency of Tfh cells expressing CXCR3, a chemokine receptor implicated in the trafficking of effector T cells into lymphoid organs (33), was increased in $\mathrm{HIV}^{+}$individuals (Supplemental Figure 1, A and C). Thus, LNs from ART-treated $\mathrm{HIV}^{+}$volunteers exhibit a potentially higher GC activity compared with HCs.

In the circulating lymphocytes, pTfh cells exhibit several functional properties reminiscent of GC Tfh cells. These features include a capacity for IL-21 secretion and the ability to promote $\mathrm{B}$ cell differentiation in vitro $(26,34)$. To determine whether HCs and $\mathrm{HIV}^{+}$patients harbored differences in their respective circulating pools of $\mathrm{CXCR}^{+} \mathrm{CD} 4^{+} \mathrm{T}$ cells, we measured the frequency of pTfh cells at baseline using the gating strategy shown in Supplemental Figure 1D. We found a significantly higher frequency of PD- $1^{+}$pTfh cells in $\mathrm{HIV}^{+}$compared with HC participants (Supplemental Figure 1E).

Prevaccination Tfh numbers are higher in follicles with preserved FDC networks. cART partially reverses the tissue-associated follicular damage induced by HIV (35). We investigated the follicular integrity in our samples by assessing the size of the follicular surface area, light zone/dark zone polarization, level of apoptosis, and FDC preservation. We applied multispectral confocal imaging and H\&E staining to look at the follicular architecture of inguinal LNs obtained at study entry. Where applicable, tonsils from unrelated, unvaccinated HCs were also stained with the same panel as controls (Supplemental Figure 2A). Although tonsils and LNs represent secondary lymphoid organs of different anatomical position and cellularity, B cell follicles from both tissue types display a highly similar GC topographical organization in the absence of immunopathology (36). The inclusion of tonsils hence was used to guide, in conjunction with our findings from HC LNs, the mapping of topographical changes seen in $\mathrm{HIV}^{+}$participants. We found a higher degree of follicular GC heterogeneity in $\mathrm{HIV}^{+}$participants compared with HCs (Figure 2A and Supplemental Figure 2A). Even though some "canonical" secondary follicles with a well-defined mantle zone, as denoted by $\operatorname{IgD}$ staining and Ki67 polarization, could be seen (data not shown), the majority of follicles examined in $\mathrm{HIV}^{+} \mathrm{LNs}$ harbored $\operatorname{IgD}^{+}$zones that were less easy to define, if at all present, and without a clear GC Ki67 polarization (Figure 2A). An ingression of mantle $\mathrm{B}$ cells $\left(\mathrm{IgD}^{+}\right)$into the reactive $\mathrm{GCs}$ (Figure $2 \mathrm{~A}$ ) was notable in $\mathrm{HIV}^{+} \mathrm{LNs}$, and the size of follicles was also different between the 2 groups, with B cell areas covering a higher surface area in $\mathrm{HIV}^{+} \mathrm{LNs}$ than $\mathrm{HCs}$, consistent with follicular hyperplasia and/or lysis (Figure 2A and Supplemental Figure 2, A and B) even after cART in HIV infection. The presence of follicular dendritic cell (FDC) networks was investigated by imaging analysis (see Methods). We found that higher absolute Tfh cell numbers correlated with follicles that had retained an FDC network, as calculated by surface area analysis $\left(r^{2}=0.3647, P=0.0023\right)$ (Figure $2, \mathrm{~B}$ and $\mathrm{C}$ ). In addition, we employed an in situ cell death assay (TUNEL) that allows for the detection of dead cells with respect to their localization. We found lower levels of TUNEL ${ }^{+}$events in HC LN follicles $\left(145 \pm 224\right.$ cells $/ \mathrm{mm}^{2}$ versus $273 \pm 271$ for $\left.\mathrm{HIV}^{+}\right)$ (Figure 3, A and B), consistent with a higher level of cellular death in follicles of $\mathrm{HIV}^{+}$participants. We opted for enumeration of total TUNEL ${ }^{+}$events per follicle, as the downregulation of cell surface markers during apoptosis precluded the measurement of cellular death within individual cell subsets. Our data show that, in treated $\mathrm{HIV}^{+}$infection, despite the presence of a generalized perturbation in follicular architecture, Tfh cell numbers are higher in those follicles that maintain a level of architectural integrity, as judged by the presence of FDCs.

Vaccination induces relevant follicular B cell populations. Next, the dynamics of follicular B cell populations before and after vaccination were investigated by applying a polychromatic flow cytometry panel for the detection of follicular B cell subsets, particularly those expressing the $\mathrm{CD} 2 \mathrm{O}^{\text {hi }}$ phenotype, an abundant B cell population within the GC. The gating strategy adopted for $\mathrm{B}$ cell phenotyping in LN cell suspension is shown in Figure 
A

$\begin{array}{ccc}\text { Study entry } & \text { Influenza } & 2^{\text {nd }} \mathrm{LN} \\ 1^{\text {st } L N} \text { biopsy } & \text { Vaccination } & \text { biopsy }\end{array}$

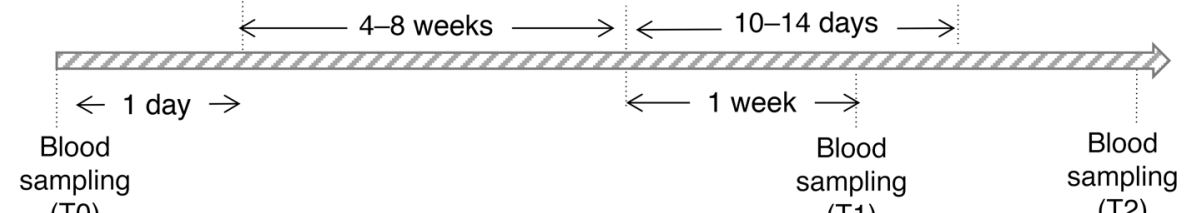

(T0)

(T1)

(T2)

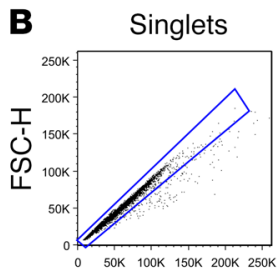

FSC-A

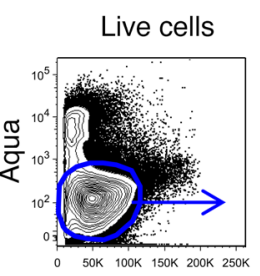

FSC-H

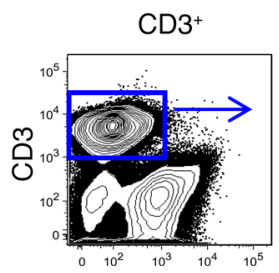

CD20

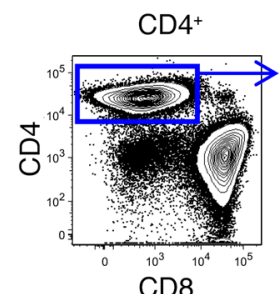

CD8
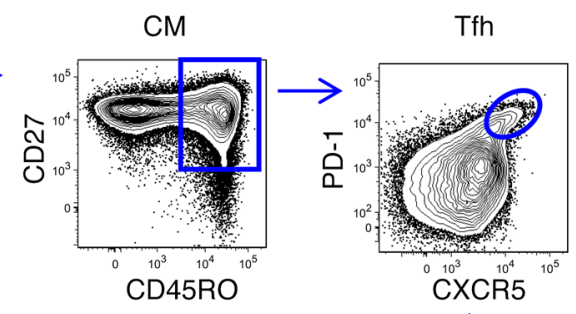
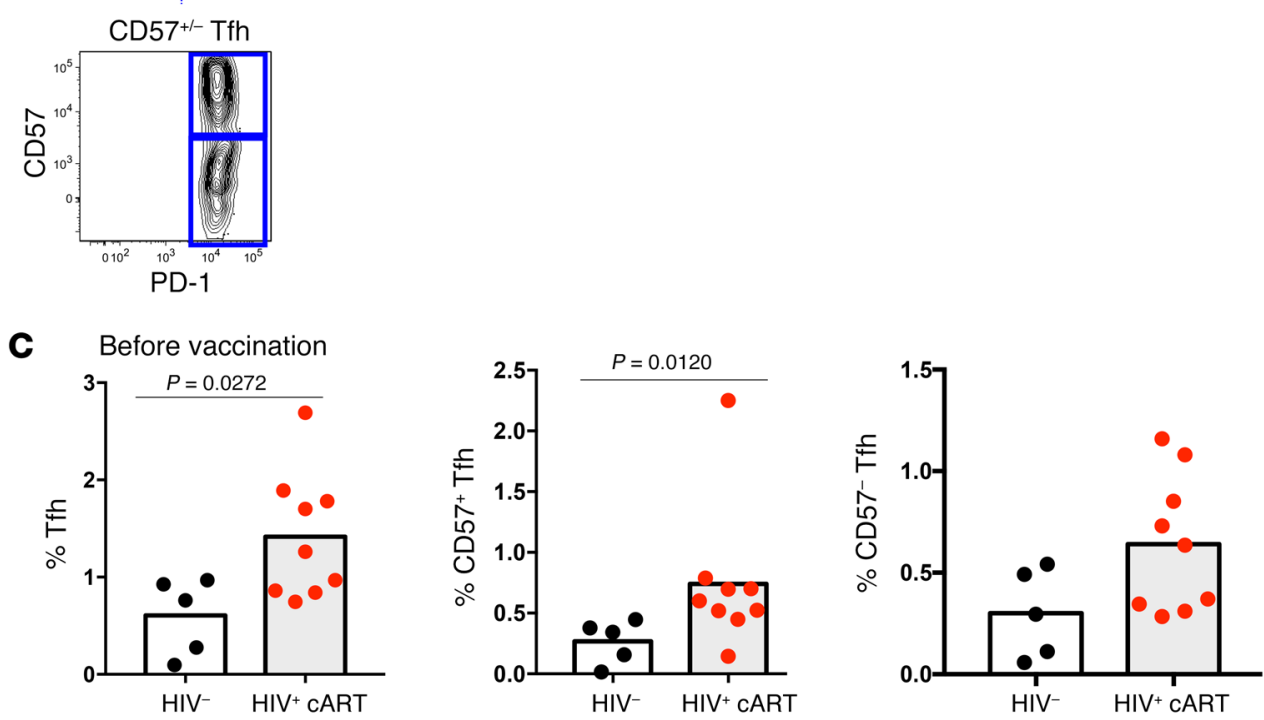

Figure 1. HIV+ LNs harbor higher frequencies of Tfh cells before vaccination compared with HC LNs. (A) Schematic of study sampling. (B) Gating strategy used for Tfh cell characterization in LN cell suspensions using flow cytometry. (C) Pooled data showing the frequency of Tfh cells before vaccination in HCs $(n=5)$ and $\mathrm{HIV}^{+} \mathrm{LNs}(n=9)$. Data represent mean values unless indicated otherwise. The Mann-Whitney test was used for statistical analysis.

4A. We found a significantly lower frequency of memory B cells in the LNs of infected individuals compared with controls $(P=$ $0.0192 / P=0.0380$, Mann-Whitney $U$ test) (Supplemental Figure $3 \mathrm{~A})$. Although not significant, a trend for a higher percentages of $\mathrm{CD} 27^{\text {hi }} \mathrm{IgD}^{\mathrm{lo}}$ or $\mathrm{CD} 2 \mathrm{O}^{\mathrm{dim}} \mathrm{CD} 38^{\mathrm{lo}}$ memory B cells after vaccination was found selectively in $\mathrm{HIV}^{+}$participants (Supplemental Figure $3 \mathrm{~A}$ ), while no differences were found in the $\mathrm{CD} 2 \mathrm{O}^{\mathrm{hi}} \mathrm{CD} 38^{\mathrm{dim}}$ and $\mathrm{CD} 2 \mathrm{O}^{\mathrm{lo}} \mathrm{CD} 38^{\text {hi }}$ compartments (Figure $\left.4 \mathrm{~B}\right)$. Furthermore, a significant induction of the $\mathrm{IgG}^{+} \mathrm{Ki}^{-} 7^{-}$population was observed after vaccination selectively in the $\mathrm{CD} 2 \mathrm{O}^{\mathrm{dim}} \mathrm{CD} 38^{\text {lo }}$ memory $\mathrm{B}$ cell compartment of $\mathrm{HIV}^{+}$individuals $(P=0.0270$, Mann-Whitney test) (Figure 4C and Supplemental Figure 3B). A similar increase was not seen among $\mathrm{IgG}^{+} \mathrm{Ki} 67^{+} \mathrm{CD} 2 \mathrm{O}^{\mathrm{dim}} \mathrm{CD} 38^{\text {lo }}, \operatorname{IgG}^{+} \mathrm{Ki}^{6} 7^{+} \mathrm{CD} 2 \mathrm{O}^{\text {hi }}$ $\mathrm{CD} 38^{\text {dim }}$ and $\mathrm{IgG}^{+} \mathrm{KI}^{-} \mathrm{CD} 2 \mathrm{O}^{\mathrm{hi}} \mathrm{CD} 38^{\mathrm{dim}} \mathrm{B}$ cells in either $\mathrm{HIV}^{+}$participants or HCs (Supplemental Figure 3B). We also evaluated the percentages of circulating memory $\mathrm{B}$ cells before and after vaccination in the 2 donor groups using peripheral blood mononuclear cells (PBMCs) and polychromatic flow cytometry using the gating strategy shown in Figure 4A. Analysis of PBMC samples did not reveal significant changes in the circulating memory B cell compartments in either $\mathrm{HCs}$ or treated $\mathrm{HIV}^{+}$participants after vaccination (data not shown). Taken together, our data show that vaccination induces relevant memory B cell populations at the tissue level in treated $\mathrm{HIV}^{+}$participants.

Tfh cell frequencies before vaccination predict responses to influen$z a$ B antigen. Tfh cells play a key role in the development of humoral responses following infection and vaccination $(37,38)$. We thus sought to determine whether baseline Tfh cell frequencies could predict the response to vaccination in terms of individual responses to influenza antigens for which antigenic probes were available. hemagglutinin inhibition assay (HIA) was performed as previously published (13). We found that $\mathrm{HIV}^{+}$participants that mounted higher titers following vaccination (strong responders, with equal or greater than a 16 -fold difference in titer versus the baseline as 
A GCs before vaccination
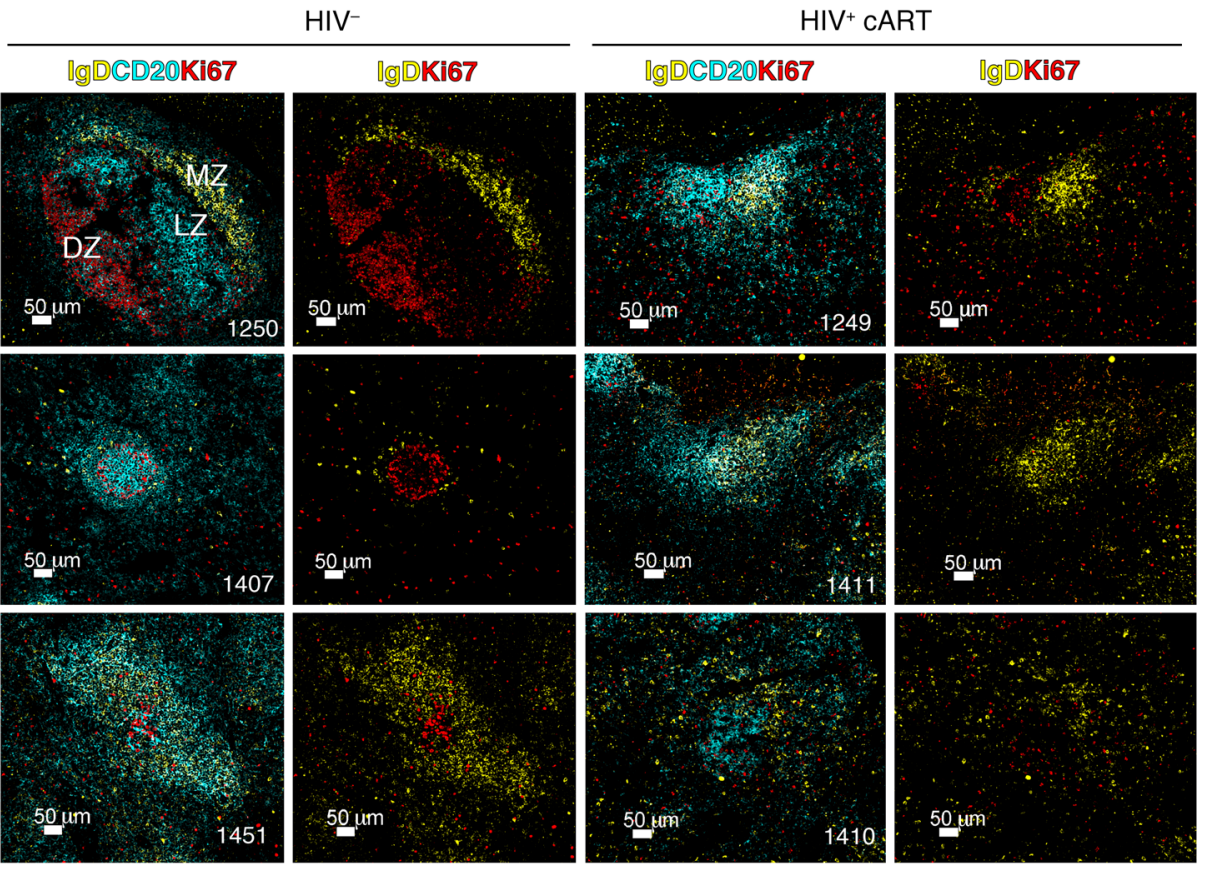

B FDC networks before vaccination $\left(\mathrm{HIV}^{+} \mathrm{CART}\right)$
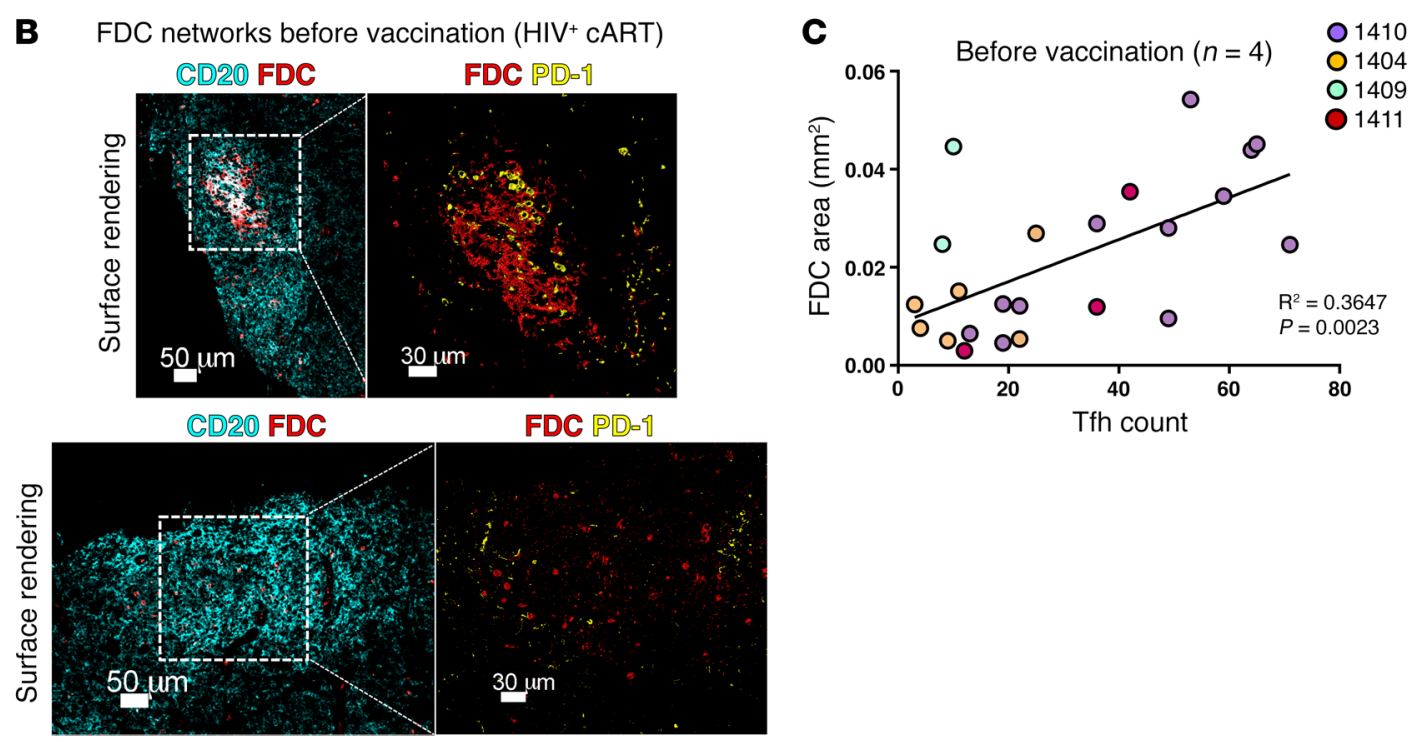

Figure 2. LN follicles with preserved FDC networks in treated HIV infection have higher absolute numbers of Tfh cells. (A) Representative confocal imaging examples showing the architecture of secondary follicles in $\mathrm{HCs}$ and HIV+ LNs. Tissue sections were stained with anti-CD20 (cyan) for B cell follicle identification, IgD (yellow) for the visualization of mantle zone, and the proliferation marker Ki67 (red) for dark zone/light zone delineation. MZ, mantle zone; LZ, light zone; DZ, dark zone. Scale bars: $50 \mu \mathrm{m}$. (B) Representative confocal imaging surface renderings of B cell follicles in treated HIV infection containing preserved (upper panels) or fragmented (lower panels) FDC networks. Scale bars: $50 \mu \mathrm{m} ; 30 \mu \mathrm{m}$ (detail). (C) Linear regression plot showing the correlation between the total area of the FDC network in each follicle and absolute Tfh cell count as measured using histocytometry. Each dot represents an individual follicle, and follicles from a single tissue section are color coded according to patient ID $(n=4)$. Original magnification, $\times 40$ (NA 1.3).

measured by HIA) had higher frequencies of Tfh cells before vaccination compared with weak responders, who did not mount as strong responses $(1.78 \% \pm 0.7 \%$ versus $1.1 \% \pm 0.5 \%$, Figure $5 \mathrm{~A})$. In addition, Tfh and $\mathrm{CD} 57^{+} \mathrm{Tfh}$ cell frequencies at baseline, but not those of $\mathrm{CD} 57^{-} \mathrm{Tfh}$ cells, could predict the response to the less frequently encountered (39) influenza subtype B antigen (Figure $5 \mathrm{~B})$. However, no correlation was seen for $\mathrm{Tfh}$ cells and the more frequently encountered H1N1 antigen (Supplemental Figure 4A) or H3N1 (data not shown) in our donors. Contrary to HIV donors, no correlation was found between the percentage of Tfh cells and the vaccine responses to $\mathrm{B}$ cell antigen in HC donors (Supplemental Figure 4A). Since B cell analyses had indicated an increase in $\mathrm{IgG}^{+} \mathrm{Ki}^{-} \mathrm{CD} 2 \mathrm{O}^{\mathrm{dim}} \mathrm{CD} 38^{\text {lo }}$ memory $\mathrm{B}$ cells after vaccination in treated $\mathrm{HIV}^{+}$infection, we also performed linear regression to evaluate whether the percentages of $\mathrm{IgG}^{+} \mathrm{Ki} 67^{-} \mathrm{CD} 2 \mathrm{O}^{\mathrm{dim}} \mathrm{CD} 38^{\text {lo }}$ memory $\mathrm{B}$ cells after vaccination had an equal predictive val- 
A Before vaccination

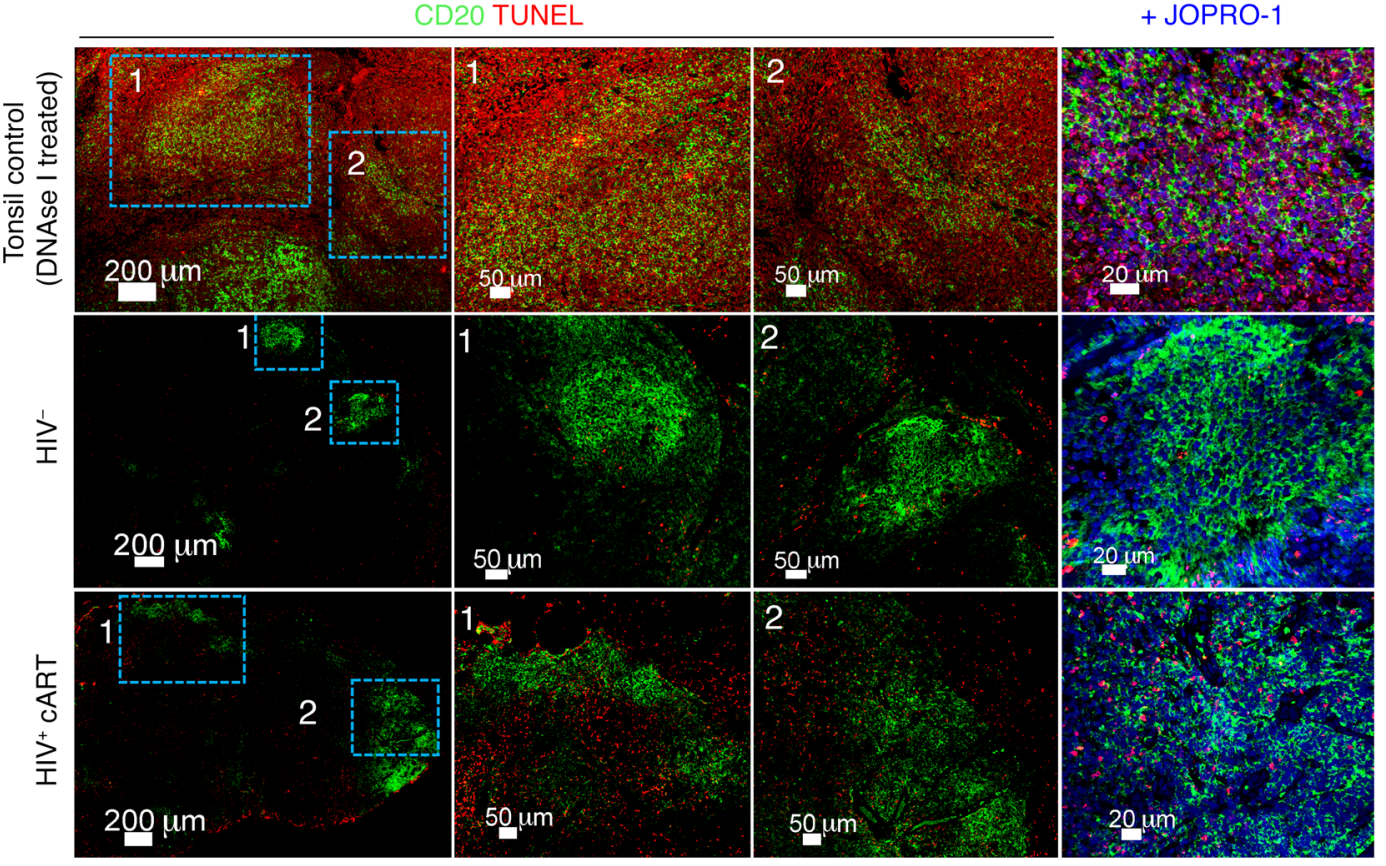

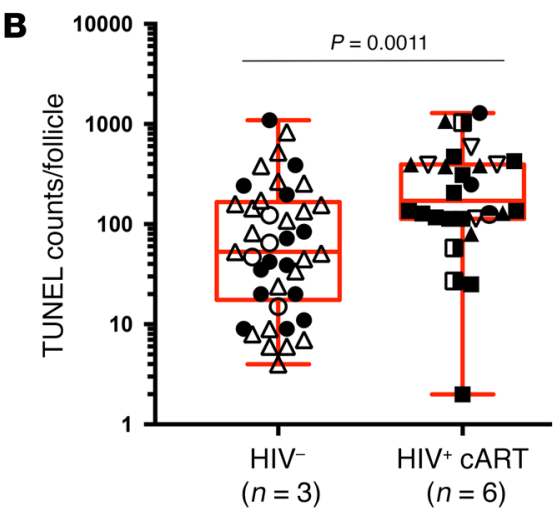

Figure 3. Higher levels of cell death in LNs of HIV+ participants at baseline. (A) Representative confocal images of LN sections labeled with anti-CD20 (green) and TUNEL (red) for the detection of apoptotic DNA fragmentation in HC and HIV+ LNs (middle and lower panels). A tonsil treated with DNAse I (upper row) was also included in the assay to control for validity and staining specificity. Individual cells were detected using the nuclear dye JOPRO-1.

(B) Cumulative histocytometry measurements for intrafollicular TUNEL+ events before vaccination in HC $(n=3)$ and $\mathrm{HIV}^{+}(n=6) \mathrm{LNs}$. Different symbols and colors represent different patients. Symbol repetitions represent the different follicles within each tissue. $P$ values were calculated using the Mann-

Whitney $t$ test. Original magnification, $\times 40$.

ue. A positive trend was observed between this population and influenza B antigen HIA titers (Supplemental Figure 4B) and between $\mathrm{CD} 2 \mathrm{O}^{\mathrm{dim}} \mathrm{CD} 38^{\text {lo }} \mathrm{B}$ cells and antigen-specific $\mathrm{B}$ responses (Supplemental Figure 4B), but this trend did not reach statistical significance. In aggregate, our data suggest that the baseline frequency of Tfh cells is a determinant for the development of vaccineinduced B cell responses toward the less frequently encountered influenza B antigen in treated $\mathrm{HIV}^{+}$infection.

Vaccination is associated with a reduction in frequency of $T f h$ $C D 4^{+} T$ cells. Next, we investigated the effect of vaccination on draining $\mathrm{LN} \mathrm{CD} 4^{+} \mathrm{T}$ cell dynamics. The relative frequencies of $\mathrm{LN}$-derived $\mathrm{CD} 4^{+} \mathrm{T}$ cells were analyzed by applying a polychromatic flow cytometry-based assay and the gating scheme shown in Figure 1B. Comparative analysis revealed a significant reduc- tion of Tfh cell frequency (expressed as a percentage of total $\mathrm{CD} 4^{+} \mathrm{T}$ cells) after vaccination $(1.54 \% \pm 0.7 \%$ before vaccination versus $0.89 \% \pm 0.45$ after vaccination) in $\mathrm{HIV}^{+}$donors (Figure $6 \mathrm{~A})$. Further analysis of Tfh cell populations based on the expression of $\mathrm{CD} 57$ showed a reduction of both $\mathrm{CD} 57^{+}$and $\mathrm{CD} 57^{-}$subsets in $\mathrm{HIV}^{+}$donors, although the reduction was significant only in the CD57- compartment (Figure 6A). No difference, however, was found when the relative frequencies were expressed as a percentage of the parental $\mathrm{Tfh}$ population (\% of Tfh), a surrogate of the intrinsic capacity of the parental population to adopt the phenotypes under investigation (Supplemental Figure 5A). The reduction in the frequency of Th cells within GCs was also confirmed using fluorescent confocal imaging (Figure 6B). These results demonstrate that vaccination is associated with an overall 
A

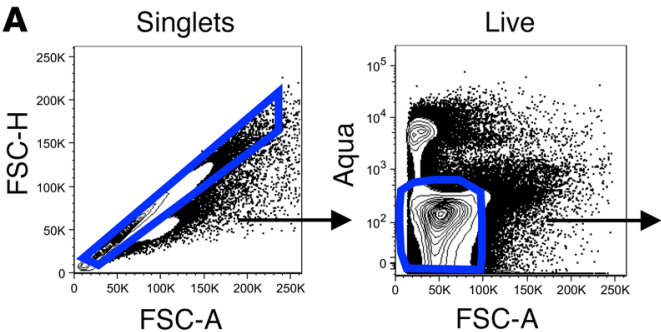

FSC-A

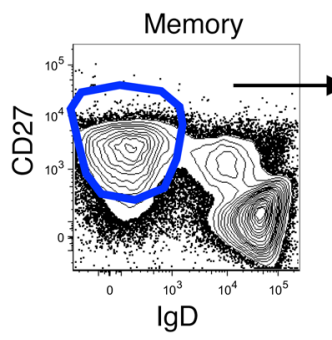

FSC-A

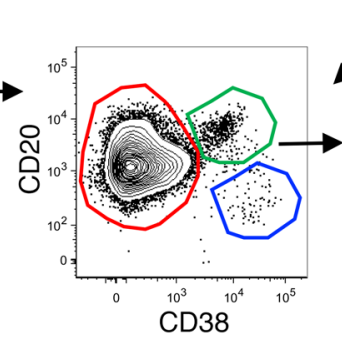

HIV CART

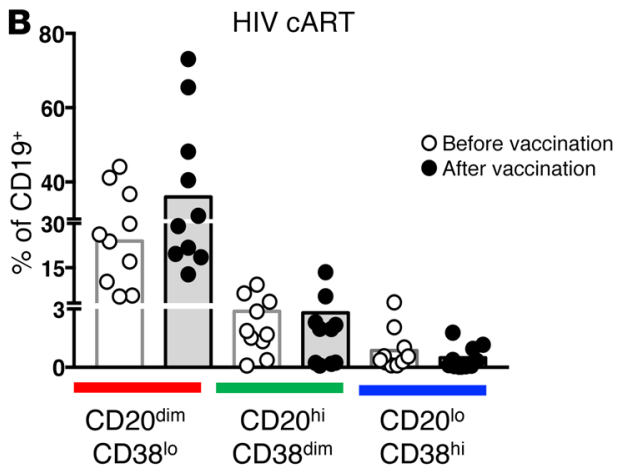

C

lgG+ $\mathrm{Ki}^{-} 7^{-}$within $\mathrm{CD}_{20} \mathrm{O}^{\mathrm{dim}} \mathrm{CD} 38^{10}$
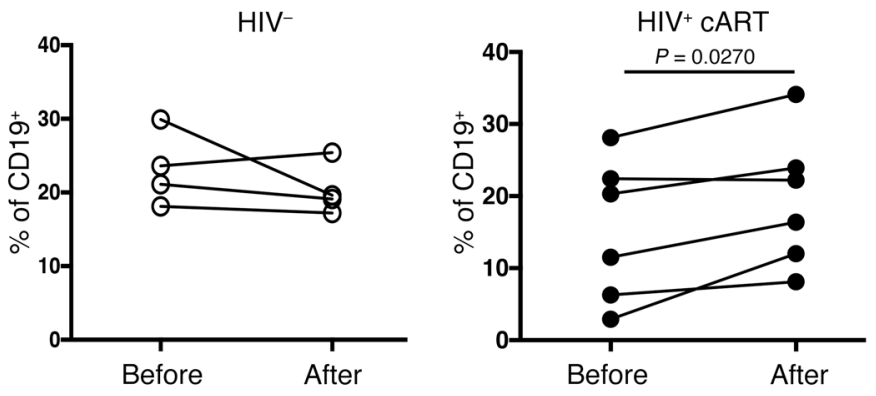

B cells

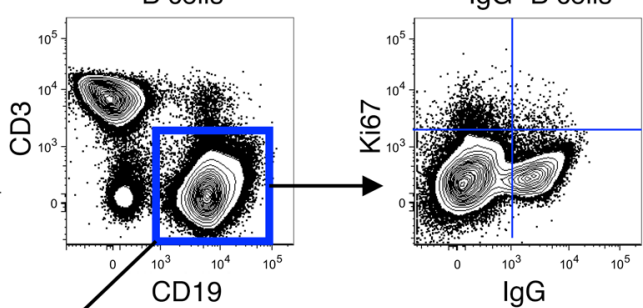

CD19
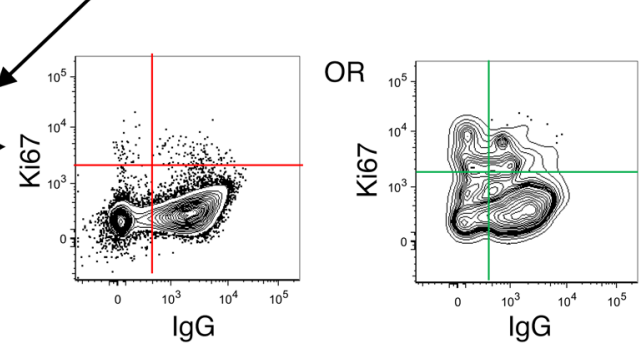

Figure 4. Vaccination increases the frequency of $\mathrm{CD}^{20^{\text {dim }}} \mathrm{CD} 8^{10}{ }^{\circ} \mathrm{gC}^{+}$ B cells. (A) Flow cytometry gating strategy used for B cell phenotyping in draining $L N$ cell suspensions from a representative $\mathrm{HIV}^{+}$donor before vaccination. (B) Cumulative frequencies of $B$ cells (CD19+) within the $\mathrm{CD} 2 \mathrm{O}^{\mathrm{hi}}, \mathrm{CD} 2 \mathrm{O}^{\mathrm{dim}}$, and $\mathrm{CD} 2 \mathrm{O}^{\mathrm{lo}}$ memory compartments before and after vaccination (C) Plots summarizing the frequencies of $\mathrm{CD} 2 \mathrm{O}^{\mathrm{dim}} \mathrm{CD} 38^{10}$ IgC ${ }^{+} \mathrm{Ki}^{-} 7^{-}$cells in paired pre- and postvaccination samples from $\mathrm{HCs}$ $(n=4)$ (white circles) and treated $\mathrm{HIV}^{+}(n=6)$ participants (black circles). $P$ value determined by Mann-Whitney $t$ test. reduction of Tfh cells in draining LNs, a profile specifically found in $\mathrm{HIV}^{+}$individuals.

Imaging analysis reveals a generalized reduction of Tfh cells. Tfh cell dynamics were further investigated by multiparameter histocytometry, a quantitative confocal imaging analysis that allows for the representation of confocal images in a 2D flow cytometric format $(40,41)$. We employed a multiplexed assay to simultaneously detect 5 protein markers of interest, namely, CD20, Ki67, CD4, PD-1, CD57, and examined the numbers of Tfh cells in paired preand postvaccination $\mathrm{LN}$ samples from $3 \mathrm{HIV}^{+}$individuals (Supplemental Table 1). GCs were defined based on the coexpression of CD20 and Ki67, as shown in Figure 7A. In agreement with our flow cytometry data, we found a reduction in the normalized (cells/ $\mathrm{mm}^{2}$ ) numbers of Tfh cells in GCs after vaccination (Figure 7B). We also sought to investigate whether the loss of Tfh cells after vaccination could be associated with a loss of follicular architecture, as judged by the absence of FDC networks. In contrast with the prevaccination profile, no correlation was observed between the area of the FDC network $\left(\mathrm{mm}^{2}\right)$ and the absolute counts of Tfh cells after vaccination (Supplemental Figure 5B). To complement our analysis, we also assessed whether the observed loss could arise from an infiltration of follicular CD8 (fCD8). We defined fCD8 $\mathrm{T}$ cells based on CXCR5 and CCR7expression (CCR7 $7^{\text {lo }}$ CXCR5 $5^{\text {hi }}$, as previously published (41). In accordance with previously published data (41), we found a trend for accumulation of $\mathrm{fCD}^{+} \mathrm{T}$ cells in treated $\mathrm{HIV}^{+}$infection using multiparameter flow cytometry of LN suspensions (Supplemental Figure 5C). When paired prevaccination and postvaccination samples from $4 \mathrm{HIV}^{-}$ and $6 \mathrm{HIV}^{+}$participants were analyzed, no consistent effects of vaccination emerged on the relative frequencies of $\mathrm{LN} \mathrm{fCD} 8^{+} \mathrm{T}$ 


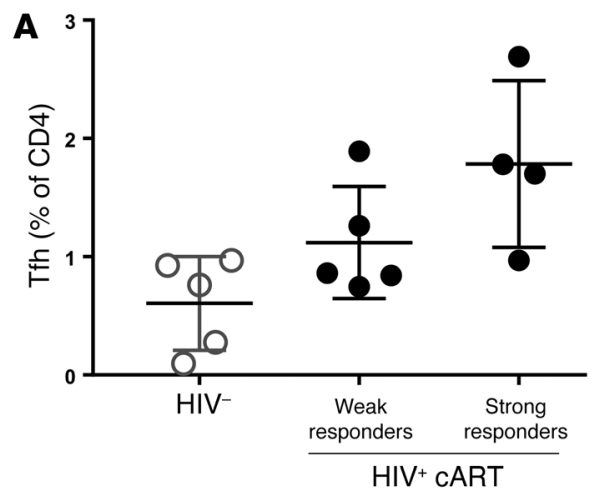

Figure 5. Prevaccination Tfh cell frequencies predict responses to influenza B antigen. (A) Percentages of Tfh cells before vaccination in HCs and $\mathrm{HIV}^{+}$participants with either weak ( $<8$-fold increase) or strong ( 216 -fold increase) response to vaccination as measured by HIA. (B) Percentages of Tfh cells (including $\mathrm{CD} 57^{+}$and $\mathrm{CD} 57^{-} \mathrm{Tfh}$ ) before vaccination as a function of the fold difference in influenza $B$ antigen (B ag) HIA titers. Lines indicate correlations determined by linear regression analysis ( $n=8$ for all graphs).
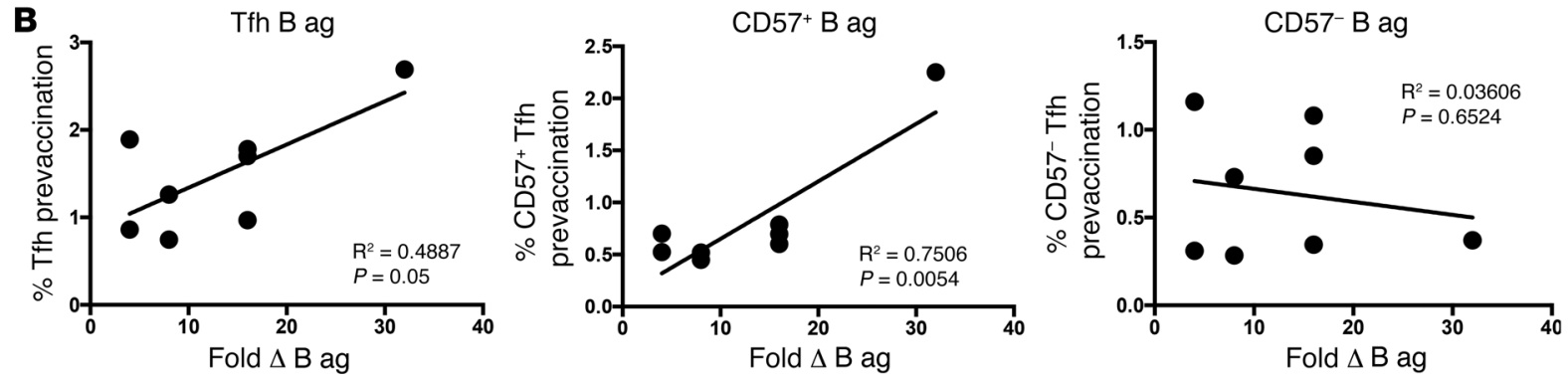

cells in either donor group (Supplemental Figure 6C). Thus, our results are consistent with Tfh cell loss after vaccination being a generalized phenomenon that is most likely not driven by GC $\mathrm{fCD}^{+} \mathrm{T}$ cell infiltration.

Vaccination alters Tfh cell gene signatures. Given the limited number of available LN-derived cells, we investigated gene signatures of sorted $\mathrm{CD}^{+} \mathrm{T}$ cells from $\mathrm{LN}$ suspensions before and after vaccination using the Fluidigm Biomark platform and a curated set of 96 gene primers. Analysis of Tfh cell hallmark genes before vaccination showed a differential expression among naive, non-Tfh memory, and Tfh cells both in $\mathrm{HIV}^{-}$and $\mathrm{HIV}^{+}$participants (Figure 8, A and B, and Supplemental Figure 6). Furthermore, although less evident, differences were found for certain genes between the 2 Tfh subsets (CD57 ${ }^{+}$and CD57-) (Figure 8B). Following vaccination, clustering was driven by cell type rather than vaccination time point (Figure 8C). Evaluation of individual genes, however, revealed that CD57- ${ }^{-}$ffh cells in $\mathrm{HIV}^{+}$samples increased activation markers, such as CD69, CXCL1O, and CCR5, and that this was not observed in the same cells in $\mathrm{HIV}^{-} \mathrm{LNs}$ or $\mathrm{CD}^{2} 7^{+} \mathrm{Tfh}$ cells from $\mathrm{HIV}^{+}$donors (Figure 8D). In HIV individuals, specific genes involved in Th cell function, namely, CXCR5, BCL6, IL6RA, and IL6ST (Figure 8D), were induced by vaccination within the $\mathrm{CD} 57^{+} \mathrm{Tfh}$ cell compartment, while this pattern was absent from $\mathrm{HIV}^{+}$Tfh cells.

\section{Discussion}

The interplay among follicular structure, Tfh cell dynamics, and $B$ cell responses in chronic human infections is not well understood. We used LNs from cART-treated $\mathrm{HIV}^{+}$participants who received trivalent seasonal influenza vaccination. We applied multiparametric flow cytometry and advanced multiplexed confocal imaging to model these interactions. Where applicable, tonsils from unrelated HCs were also included in our microscopy studies. Although B cells constitute the largest cellular compartment in tonsils, imaging analysis of these tissues allows a topographic mapping of B cell follicular subareas (mantle zone, GCs, light and dark zones, and FDC network) of high resolution $(36,42)$. Therefore, in our analyses, tonsils were used solely for histological comparison to matched areas from $\mathrm{HC}$ and $\mathrm{HIV}^{+} \mathrm{LNs}$. We demonstrate that influenza vaccination alters the cellularity of draining LNs of $\mathrm{HIV}^{+}$persons in conjunction with the development of antigenspecific humoral responses. Understanding the dynamics supporting the development of antibody responses in $\mathrm{HIV}^{+}$persons is critical for the rational design of future vaccine strategies. However, follow-up biopsy studies in treated $\mathrm{HIV}^{+}$persons remain relatively scarce due to the difficulty in obtaining the necessary study material. From this standpoint, the data presented herein offer a unique and valuable insight into the tissue-specific changes that ensue following vaccination in treated $\mathrm{HIV}^{+}$persons, especially with regard to cellular subsets, such as FDCs, that are challenging to study ex vivo or in vitro due to their fragility in relation to mechanical and chemical stress $(43,44)$.

In agreement with previous studies $(22,23)$, we report a significant $(P=0.0272)$ enrichment of Tfh cells (identified by high expression of PD-1 and CXCR5) in the LNs of $\mathrm{HIV}^{+}$patients compared with HCs. To further understand the possible role of Tfh cell subsets, we dissected this population based on the expression of the glycoprotein CD57, a marker of higher differentiation and senescence of circulating T cells (45). In our study, both CD57 ${ }^{+}$ and $\mathrm{CD}^{-} 7^{-} \mathrm{Tfh}$ populations were enriched in the follicles of $\mathrm{HIV}^{+}$ individuals, particularly the $\mathrm{CD} 57^{+}$ones. It has been proposed that $\mathrm{CD} 57^{+} \mathrm{Tfh}$ cells may have an increased potential for GC B cell help $(28,46)$. This is further substantiated by their relative positioning proximally to the DZ in "canonical" GCs (Supplemental Figure 2C). Thus, it is plausible that $\mathrm{HIV}^{+}$individuals may harbor a differential potential for quicker vaccination-induced $\mathrm{B}$ cell mobilization at baseline compared with HCs given their higher $\mathrm{CD} 57^{+} \mathrm{Tfh}$ 
A
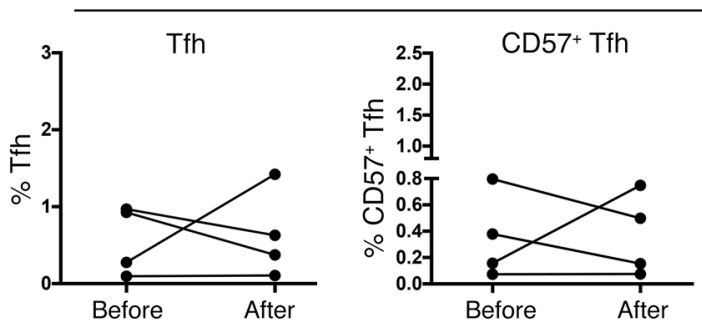

HIV+CART

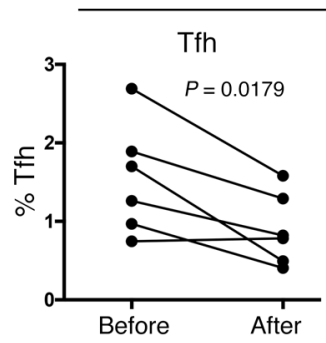

CD57+ Tfh

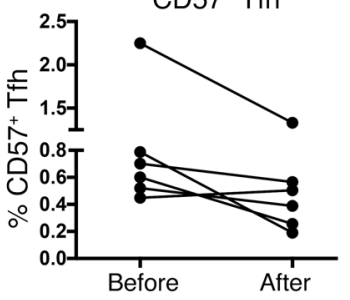

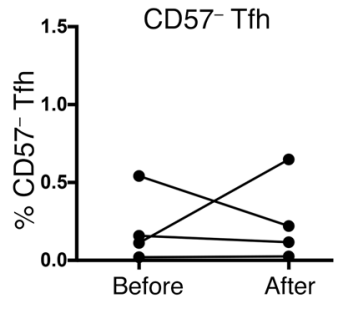

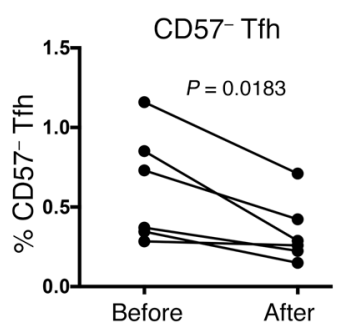

B

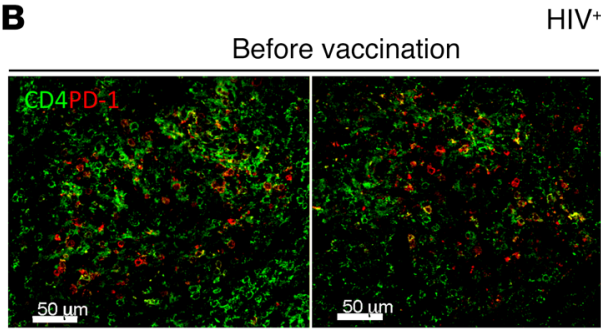

HIV+ cART

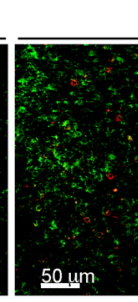

After vaccination
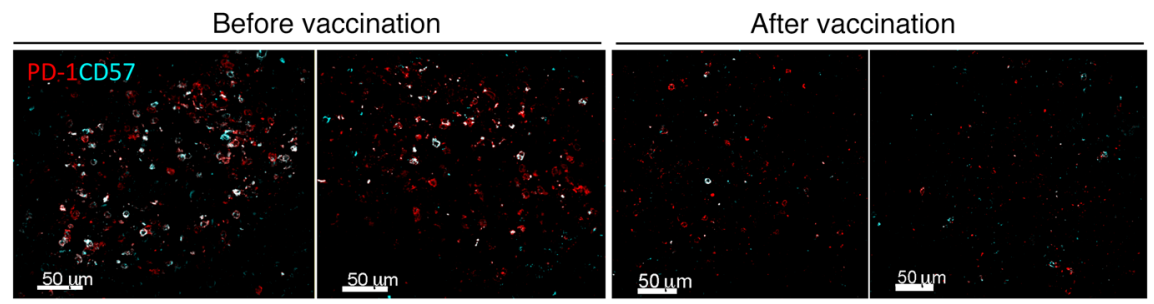

Figure 6. Vaccination lowers the frequency of Tfh cells in HIV+ LNs. (A) Pooled data showing the frequency of Tfh cells at the before and after vaccination time points in $\mathrm{HC}(n=4)$ and $\mathrm{HIV}^{+} \mathrm{LNs}(n=6)$, as measured by polychromatic flow cytometry. (B) Representative confocal images of follicles from a single $\mathrm{HIV}^{+}$donor before and after influenza vaccination showing the distribution of CD4 (green), PD-1 (red), and CD57 (cyan) within CCs and the loss of Tfh after vaccination. The Mann-Whitney $U$ test was used for statistical analysis. Scale bars: $50 \mu \mathrm{m}$. Original magnification, $\times 40$ (NA 1.3). cell frequencies. However, how these higher frequencies might affect the development of antibody responses in the context of a skewed $\mathrm{CD} 7^{+}$Tfh distribution (Supplemental Figure 2C) is not known and warrants investigation. It is also currently unknown whether CD57 marks senescence for follicular CD4 $4^{+} \mathrm{T}$ cells, as in the case of circulating T cells (47).

Our phenotypic analysis revealed further marked enrichment of Tfh cells displaying an ICOS ${ }^{\text {hi }}$ LAM ${ }^{\text {hi }}$ or CXCR $3^{\text {hi }}$ phenotype. Previous studies have shown that ICOS, SLAM, and CXCR3 could be positive regulators for the development of B cell responses (31, 48). We have previously shown that SLAM ${ }^{\text {hi }}$ Tfh cells from SIVinfected nonhuman primates produce a considerable amount of IL-10, a regulator of Tfh cell responses $(49,50)$, while having a higher capacity for in vivo proliferation compared with SLAM ${ }^{\text {lo }}$ Tfh cells (24). In addition to a higher frequency of Tfh cells expressing a SLAM ${ }^{\text {hi }}$ phenotype, SLAM expression was higher per cell (as judged by the MFI, Supplemental Figure 1B) in $\mathrm{HIV}^{+}$ individuals compared with HCs. Therefore, in line with our previously published observations in SIV infection (24), HIV infection increased the complexity of the Tfh compartment by changing the profile of Tfh cells in a way that could have an impact upon the function of Tfh subsets.

In our study, B cell follicles with intact FDC networks were more likely to harbor high frequencies of activated Tfh cells at baseline in an environment with overall higher immune activation, as supported by the increased rates of cell death found in the follicular areas of $\mathrm{HIV}^{+}$participants. FDCs form a relatively extended stromal cell network, representing a major producer of CXCL13 as well as growth factors, such as BAFF, IL-6, and IL-15, that are necessary for the proliferation and maintenance of B cells (51-54). The $\mathrm{T}$ cell area collagen deposition and fibrosis $(4,6,55,56)$ as well as the fibroblastic reticular cell (FRC) and FDC depletion that occur in HIV infection have been shown to profoundly affect the activation, population expansion, and effector function of viral antigen-specific $\mathrm{T}$ lymphocytes and to impair B cell viability and GC formation $(6,52,54,55,57-61)$. ART reverses this damage, but the kinetics of this reversal is highly variable among patients $(7,35,62)$. In addition, the loss of $\mathrm{CD}^{+} \mathrm{T}$ cells in HIV infection correlates with weaker antibody responses to influenza vaccination and impaired long-term serological memory to non-HIV anti- 
A
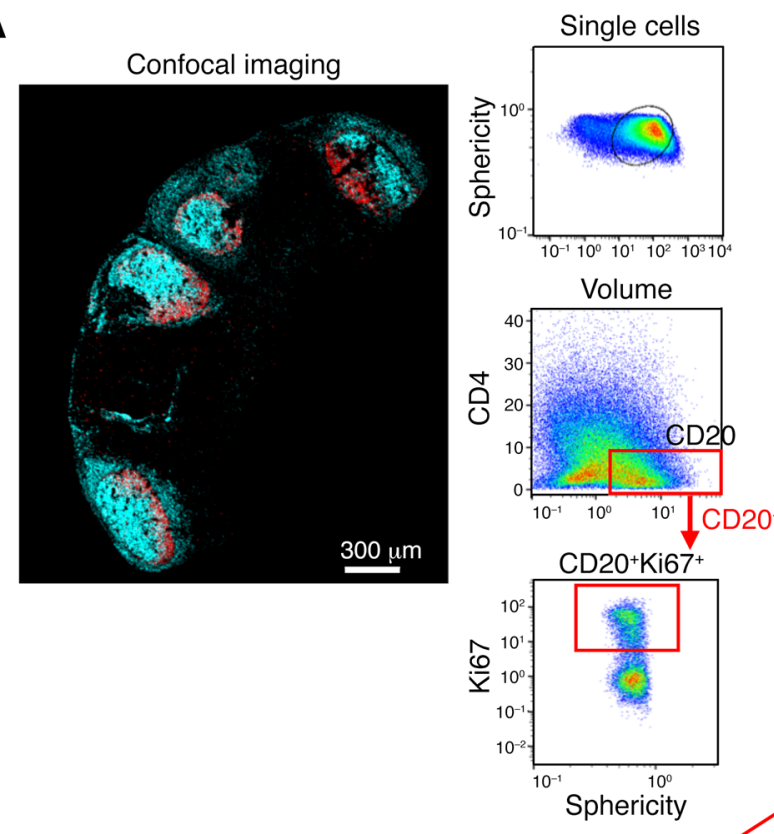

Analysis example (GC1)

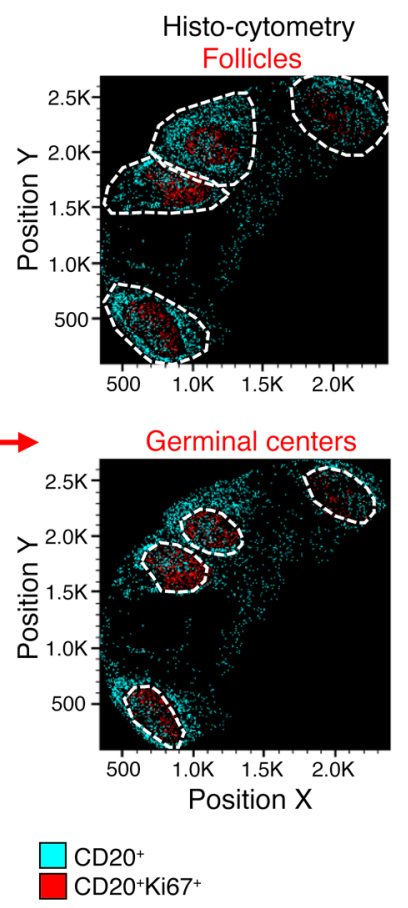

Figure 7. Generalized loss of Tfh cells after vaccination. (A) Gating strategy for $\mathrm{CD}^{+}$phenotyping in tissues using histocytometry. For the analysis, tissues were stained with anti-CD2O and anti-Ki67 for $B$ cell follicle characterization as well as anti-PD-1, CD57, and CD4 for Tfh cells. The nuclear marker J0j0-1 was also included in the analysis to aid with computational cell segmentation. Confocal images were transformed to Flowjo files as previously described, and Tfh cell frequencies within individual GCs were calculated using Flowjo, as per the analysis example. GCs were defined by gating onto $\mathrm{Ki} \mathrm{7}^{+}$rich areas of high or $\operatorname{dim}$ CD20 expression before calculating the absolute numbers of Tfh cells within each GC gate. Original magnification, $\times 40$ (NA 1.3). (B) Pooled data of Tfh cell numbers within the GCs from $3 \mathrm{HIV}^{+}$donor LNs. Each symbol corresponds to an individual donor. Matched pre- and postvaccination data are presented for each donor. Different GCs within each donor's tissue are represented by repeating the corresponding symbols.
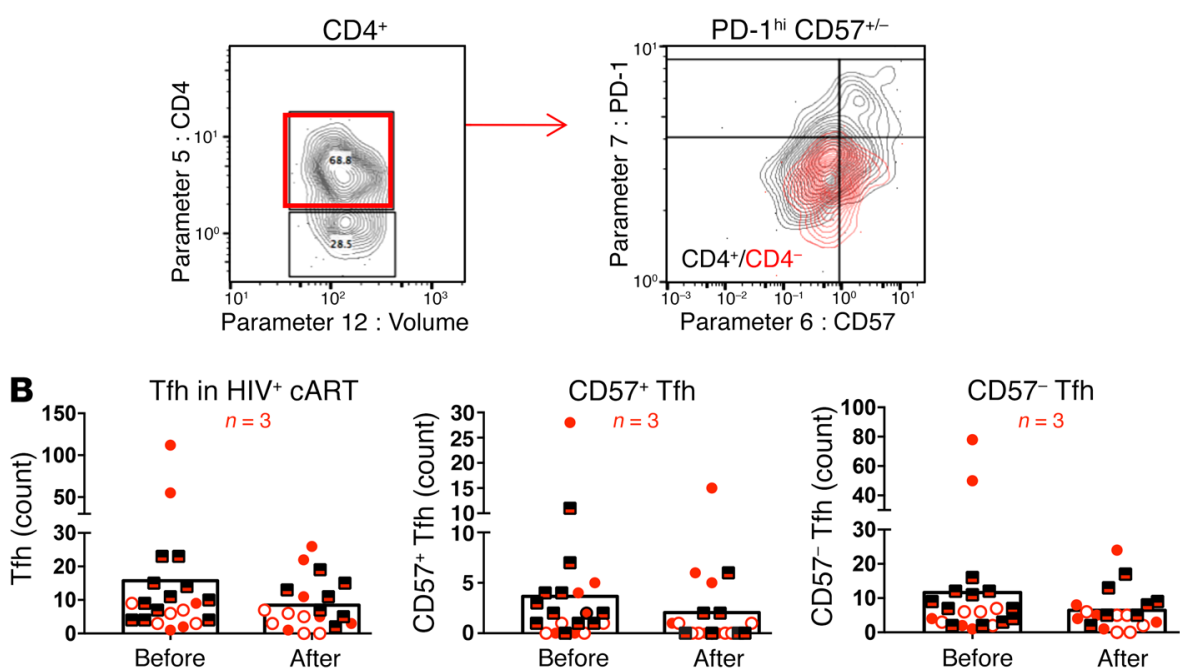

gens (63-65). However, how HIV persistence within the follicular niche affects vaccination-induced responses at tissue level is not entirely clear. In HIV disease, FDCs retain virions on their surface as immune complexes as well as in cycling endosomes for long periods of time, even under therapy $(58,59,66,67)$. Even though a characterization of the infection status of Th cells was not possible in this study, we cannot exclude that activated Tfh cells in the vicinity of virion-laden FDCs could have been targets for HIV dissemination (68). Such infected Th cells could possess an altered ability to deliver appropriate signals or timely signals for antibody production or could be increasingly susceptible to death by apoptosis. In either scenario, a suboptimal response could render the HIV-infected host vulnerable to infection $(69,70)$, further amplifying the consequences of HIV immunopathology. Alternatively, the presence of multiple competing viral antigens on the surface of FDCs may have induced B cell responses differentially in $\mathrm{HIV}^{+}$ persons compared with HCs (71). Our data thus call for further studies that could help elucidate how FDC-derived factors, such as CXCL13 and IL-6 $(52,72,73)$, could mediate the maintenance of Tfh cells in treated $\mathrm{HIV}^{+}$individuals as well as the role of viral persistence in the development of antibody responses.

The memory B cell compartment in $\mathrm{HIV}^{+}$infection is considerably harder to dissect due to the heterogeneity of the memory B cell populations (74). Chronic HIV infection causes a skewing of the B cells toward a GC and plasma cell phenotype and a loss of total memory B cells both in the LNs (22) and in the circulation (75). We found a lower frequency of memory $\mathrm{CD} 27^{\text {hi }} \mathrm{IgD}{ }^{\text {lo }} \mathrm{B}$ cells in treated $\mathrm{HIV}^{+}$participants compared with $\mathrm{HCs}$, in line with previous studies (23). A trend for higher bulk memory $\mathrm{CD} 2 \mathrm{O}^{\mathrm{dim}} \mathrm{CD} 38^{\text {lo }}$ was associated with an increase in noncycling $\mathrm{IgG}^{+} \mathrm{CD} 2 \mathrm{O}^{\mathrm{dim}} \mathrm{CD} 38^{\text {lo }}$ within the $\mathrm{CD} 27^{\mathrm{h}} \mathrm{IgD}{ }^{\mathrm{lo}}$ memory subset after vaccination. Hence, our data are consistent with local recruitment and mobilization of a nondividing memory B cell population in response to vaccination, despite the presence of disrupted follicular architecture 
A $\quad \mathrm{HIV}^{+} \mathrm{cART}$ before vaccination
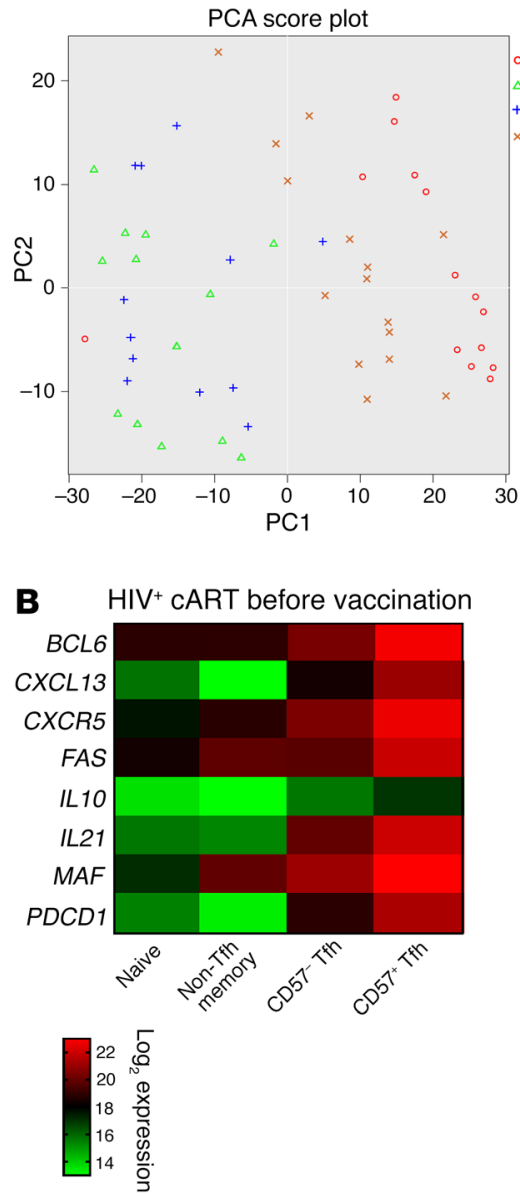

C

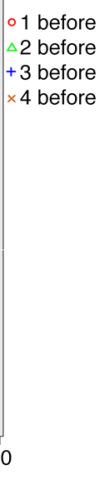

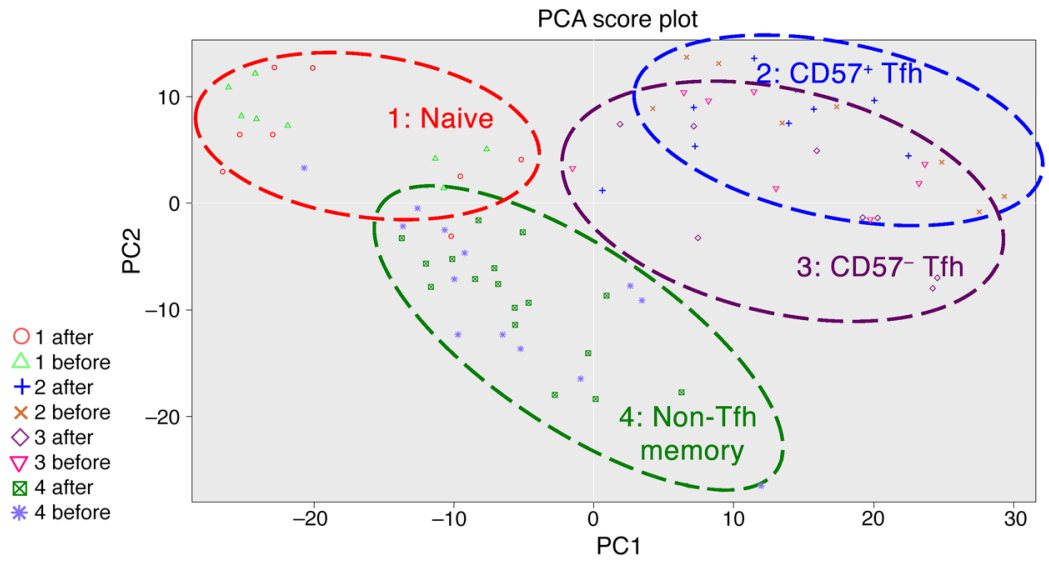

$\mathrm{HIV}^{+}$Tfh CD57-

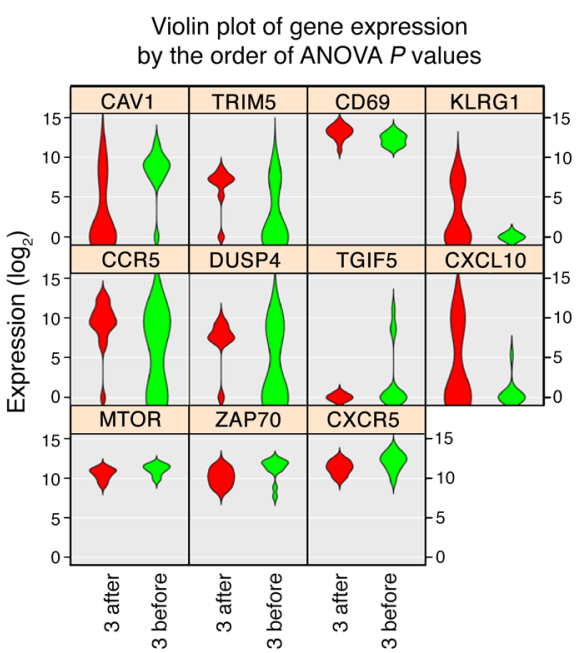

HIV- Tfh CD57-

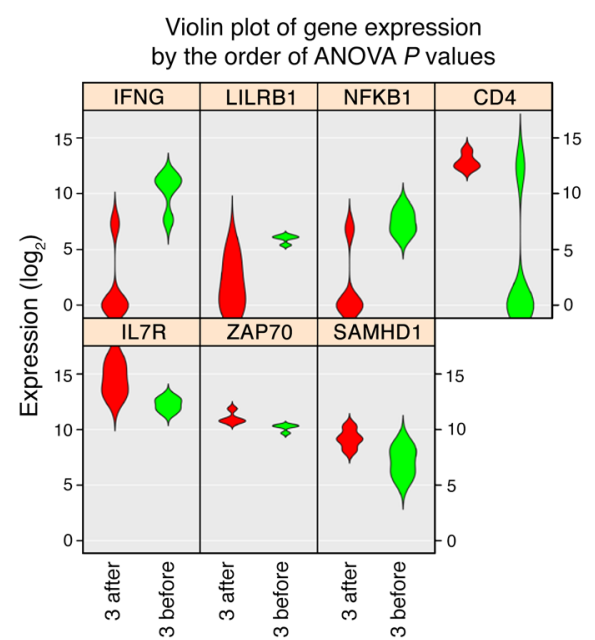

$\mathrm{HIV}^{+}$Tfh CD57+

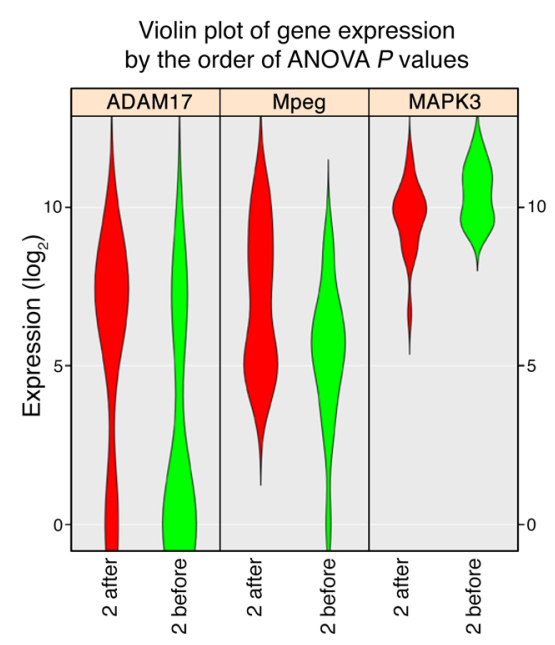

HIV- Tfh CD57+ $^{+}$

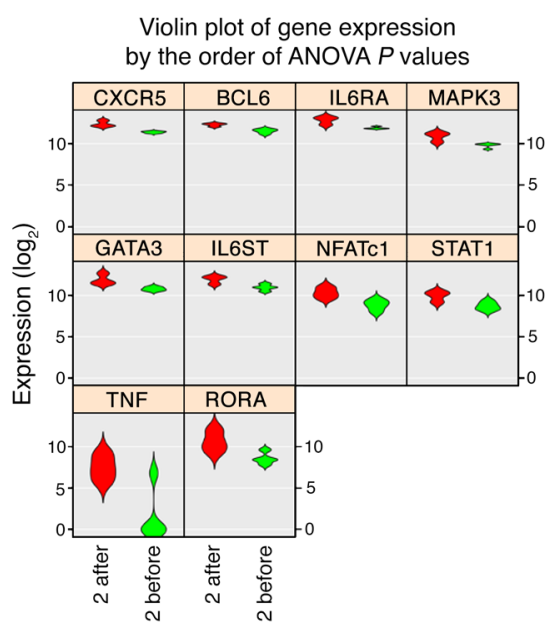

Figure 8. The gene profile of Tfh subsets is differentially affected by vaccination. (A) Principle component analysis score plot showing clustering of sort-purified LN CD4+ $4^{+}$cell subsets from treated HIV+ participants at the prevaccination time point. Subset designations are as follows: 1 , naive; 2 , $\mathrm{CD}^{-} 7^{+}$Tfh; 3, CD57- Tfh; 4, non-Tfh memory. (B) Heatmap showing the average log expression of gene transcripts involved in Tfh cell function in each sort-purified subset obtained from HIV+ participants before vaccination. (C) Principle component analysis score plot showing clustering of sort-purified subsets before and after vaccination in $\mathrm{HIV}^{+}$participants. Loops are drawn around the populations to show clustering by cell type rather than sampling time point. (D) Violin plots representing probable distribution for differential gene expression in the indicated Tfh cell types out of 96 gene targets analyzed by Fluidigm Biomark (ANOVA, $P<0.05$ ). Before vaccination is shown in green, and after vaccination is shown in red. Graphics were generated using Singular (Fluidigm). 
in these tissues. However, it is also plausible that sampling at day 14 after vaccination may not have been optimal for the detection and measurement of proliferating GC B cells. Under this scenario, an increase in the frequency of $\mathrm{IgG}^{+} \mathrm{Ki}^{-} 7^{-} \mathrm{CD} 2 \mathrm{O}^{\mathrm{dim}} \mathrm{CD} 38^{\text {lo }}$ $\mathrm{B}$ cells could represent the transition of higher frequencies of Ig $\mathrm{G}^{+} \mathrm{Ki} 67^{+} \mathrm{CD} 2 \mathrm{O}^{\mathrm{hi}} \mathrm{CD} 38^{\mathrm{dim}}$ cells at earlier time points. Longitudinal samples and nonhuman primate models could help address the observed kinetics in a more definite way.

Our findings are in line with studies reporting an expansion of the frequency of Tfh cells in LNs in response to viral persistence during the chronic stage of HIV infection. Earlier studies, however, did not address the effects of vaccination on Tfh cell dynamics. Baseline Tfh cell frequencies in our study were important because they could predict the strength of the ensuing vaccination response in $\mathrm{HIV}^{+}$persons. This was true for CXCR5 $5^{\text {hiPD }}-1^{\text {hi }}$ Tfh cells and, in particular, the $\mathrm{CD} 57^{+} \mathrm{CXCR} 5^{\text {hi }} \mathrm{PD}-\mathrm{1}^{\text {hi }} \mathrm{Tfh}$ cell population in regard to $\mathrm{B}$ antigen responses. This finding, together with the correlation of $\mathrm{CD} 7^{+} \mathrm{Tfh}$ cell frequencies before vaccination with higher postvaccination $B$ antigen titers, supports a superior capacity of $\mathrm{CD} 57^{+}$ Tfh cells for B cell help. Hence, the accumulation of Tfh cells of the $\mathrm{CD} 7^{+}$phenotype may be advantageous for the induction of $\mathrm{B}$ cell responses in treated $\mathrm{HIV}^{+}$infection. The lack of an association between Tfh cells and H1N1 or H3N1 could be attributed to the relative contribution of the 2 influenza subtypes to the total disease burden. In 2015-2016, influenza type A accounted for nearly $66 \%$ to $78 \%$ of the influenza-positive cases reported, as compared with $22 \%$ to $34 \%$ for influenza B (39). Therefore, a lower burden would make preexisting immunity to influenza B less likely and thus Tfh more relevant for this type of "primary" response. Alternatively, the prevalence of responses toward influenza type B at 2 weeks after vaccination could be indicative of differential kinetics in the processing and presentation of the 2 antigens. Preexisting immunity to influenza is also a plausible explanation for low vaccine responsiveness of HCs in our cohort. It should be noted, however, that even though some of our donors received a different formulation of the vaccine, there was no evidence of a differential segregation driven by formulation in our data set.

Interestingly, the assessment of $\mathrm{T}$ cell dynamics after vaccination revealed a reduction in the frequencies of Tfh cells, which did not appear to be $\mathrm{fCD}^{+} \mathrm{T}$ cell mediated. Although our gene analysis cannot address the manipulation of pro- or antiapoptotic pathways in Tfh cells after vaccination, the data indicate that $\mathrm{CD} 57^{+} \mathrm{Tfh}$ cells, which appear to be a more differentiated type of cell compared with their CD57- counterparts (Figure 8B), could possibly be defective in HIV. In our study, CD57 ${ }^{+}$Tfh cells could not upregulate some genes after vaccination as their counterparts in HCs did (Figure 8D). A more comprehensive gene-signature analysis would be highly informative for this issue. We argue thus that a higher level of follicular activation may have rendered these cells susceptible to death through either infection or virus-independent activationinduced death (76). The limited availability of study material, however, did not allow us to follow up on this hypothesis. One additional explanation for this phenomenon could also be that sampling at day 14 after vaccination was not optimal to detect newly generated Tfh cells that could balance the elimination of Tfh cells due to other mechanisms. This could be especially true in treated $\mathrm{HIV}^{+}$patients whose primary response kinetics may differ from those observed in
HCs. A similar reduction in Tfh frequencies has also been reported for nonhuman primates (NHPs) receiving consecutive recombinant Env trimer prime-boost vaccinations (77). It is therefore likely that this phenomenon may represent a physiological response to repeated antigenic stimulation. This finding is thus intriguing and warrants further investigation.

One drawback of our study is the relatively small sample size, especially of the HIV-negative cohort, which precludes us from drawing further conclusions. Furthermore, enrolled $\mathrm{HIV}^{+}$donors presented $\mathrm{CD} 4{ }^{+} \mathrm{T}$ cell counts and $\mathrm{CD} 4$ to $\mathrm{CD} 8$ ratios that may not be attainable by all patients on therapy. Therefore, some caution is warranted when translating such findings in the context of more divergent immunologic profiles. The lack of longitudinal LN samples also complicates the draw of mechanistic conclusions. These drawbacks are inherent to the nature and ethical considerations of our study protocol, but follow-up studies are warranted. Quantifying cell populations using imaging analysis of tissue sections also bears a risk for sampling error, as the representative value of a single imaged section cannot always be ascertained. In our case, however, similar profiles were obtained for the Tfh cell populations under investigation both by flow cytometry and tissue imaging histocytometry analysis. We therefore have crossvalidated our results using more than one experimental platform.

Our data also point to the heterogeneity of follicular dynamics, even within the same LN, as a biological parameter with a possible role in HIV pathogenesis and the development of immunogen-related antibody responses. What contributes to this heterogeneity is not well understood. To date, most of the work addressing follicular dynamics and vaccine efficacy has focused on the analysis of circulating Tfh cells and GC-related biomarkers, such as CXCL13 (78-81). However, our data revealed a dichotomy regarding the dynamics of bona fide Tfh cells and their blood counterparts, while no difference for blood levels of CXCL13 was found, at least in the patients under study (data not shown). Therefore, further studies to elucidate the LN immune dynamics after vaccination are needed. To this end, fine-needle aspiration (FNA) LN sampling in humans and longitudinal analysis of Tfh and GC B cell dynamics in NHP models would be of benefit (77). The use of NHP-derived biopsies in particular could be highly informative, especially with regard to the role of stromal cells and overall spatial organization of immune subsets, parameters that the study of $\mathrm{LN}$-derived cell suspensions alone cannot address. The existence of prior immunological memory is also important for the induction of de novo $\mathrm{B}$ cell responses in both $\mathrm{HCs}$ and $\mathrm{HIV}^{+}$individuals $(82,83)$. However, the fate of memory Tfh cells, especially in a chronic retroviral infection such as HIV, is not known $(84,85)$. Their tissue reactivation, possible retrafficking to GCs, and contribution to vaccine responses are all issues that can be addressed using NHP models. Our data suggest that responses toward individual vaccine components may have special merit as a readout in such studies. In addition, the observed reduction in Tfh cell frequency after vaccination implies that vaccine strategies employing prime-boost regimens may differ in their efficacy depending on the timing of $\mathrm{Tfh}$ cell kinetics.

In conclusion, we document that, in treated $\mathrm{HIV}^{+}$individuals, vaccination mobilizes relevant populations at the tissue level. Further studies in immunologically heterogeneous $\mathrm{HIV}^{+}$populations 
will be required to fully understand how these dynamics can be manipulated for optimal vaccine efficacy.

\section{Methods}

Study participants. The characteristics of study participants are shown in Supplemental Table 1. This study recruited and enrolled 5 HCs and 15 HIV-infected $\left(\mathrm{HIV}^{+}\right)$participants. $\mathrm{HIV}^{+}$donors were attending clinics at the University of Miami and Jackson Memorial Hospital (Miami, Florida, USA) for HIV-related monitoring prior to being recruited for this study. Eligible participants were 18 years old or older, and those with HIV had a history of HIV infection with a duration of 1 to 8 years. $\mathrm{HIV}^{+}$participants were required to have been on cART with virologic suppression (plasma HIV RNA $<20$ copies/ml) for 1 year or more with the last preentry test performed within 6 months prior to entry using the COBAS AmpliPrep/COBAS TaqMan HIV-1 Test, version 2.0. Exclusion criteria included hormonal therapy, steroids, immunosuppressant medications, and diagnosis of malignancies or other immunodeficiency disorders. Study participants were given vaccination with either trivalent Fluzone (2014-2015; Sanofi Pasteur) or Afluria (2015-2016; bioCSL Pty. Ltd.) (Supplemental Table 1) in the right thigh. Inguinal LN biopsies were obtained on the left side prior to vaccination (TO) and on the right side (draining inguinal LN) 10 to 14 days after vaccination (T1). Peripheral blood was collected within 24 hours of each LN sampling at T0 and T1 and in a subset also at 4 weeks (T2) after vaccination. Serum and plasma were stored at $-80^{\circ} \mathrm{C}$, and PBMCs and LMNCs were cryopreserved in liquid $\mathrm{N}_{2}$. Tonsils from HCs unrelated to the LN biopsy study participants were also used as controls. These specimens were discarded HIV- pathologic specimens.

Antibodies. Flow cytometry was performed using the following conjugated antibodies: CXCR5-PECy7 (clone MU5UBEE) (eBioscience); CD4-Cy55PE (clone S3.5) (Life Technologies); CD27-PC5 (clone 1A4CD27), CD45RO-ECD (clone UCHL1), CD19-ECD (clone J3-119) (Beckman Coulter); CD150-PE (clone 7D4), PD-1 BV711 (clone EH12.2H7), CD8-BV650 (clone SK1), CCR7-BV605 (clone G043H7), CD20-BV570 (clone 2H7), ICOS-PB (clone C398.4A), CXCR4-Cy7PE (clone 12G5), CD27-BV605 (clone O323) (BioLegend); CD183-APC (clone 1C6), CXCR5-FITC (clone RF8B2), IgM-Cy5PE (clone G20127), IgG-APC (clone G18-145), Ki67-AlexaFluor 700 (clone B56) (BD Biosciences - Pharmingen); (f) IgD-PE (goat polyclonal) (Southern Biotech); (g) CD3-H7APC (clone SK7) (BD Biosciences: ). CD57-Alexa Fluor 700 (clone NK1, Thermo Fisher Scientific), CXCR4-FITC (clone 12G5, Thermo Fisher Scientific), CD3-BV785 (clone OKT3, BioLegend), CD95-BV421 (clone DX2, Thermo Fisher Scientific), and CD38-BV785 (clone HIT2, Thermo Fisher Scientific) were conjugated in house. Aqua Amine Viability Dye was obtained from Invitrogen (Molecular Probes, Life Technologies). For confocal microscopy, LN tissue sections were stained with the following primary and conjugated antibodies: IgD (clone EPR 6146, Abcam), CD4-Alexa Fluor 488 (goat polyclonal, R\&D systems), CD20-eF615 (clone L26), PD-1 (goat polyclonal, R\&D Systems), CD57 (clone NK1, Thermo Fisher Scientific), Ki67-Alexa Fluor 700 (clone B56, BD Bioscience), and JOJO-1 (Life Technologies).

Polychromatic flow cytometry. PBMCs or LMNCs $\left(1\right.$ to $\left.2 \times 10^{6}\right)$, previously thawed and rested for 2 hours at $37^{\circ} \mathrm{C}$, were incubated with the Amine Dye Aqua and surface stained with titrated amounts of antibodies against CD3, CD4, CD27, CD45RO, CCR7, CXCR5, CD150, CD183, PD-1, CD20, CD8, CD57, and ICOS for T cell phenotyping or against CD3, CD19, CD20, CD27, IgD, IgM, IgG, CD38, CD95, CXCR5, and
CXCR4 for B cell phenotyping. For intracellular staining, cells were washed with PBS after surface staining, permeabilized (Cytofix/Cytoperm Kit; BD Biosciences), and stained with anti-Ki67 antibody for 20 minutes. Cells were then washed and fixed with $1 \%$ paraformaldehyde. Events were collected on a Fortessa X-50 flow cytometer (BD Immunocytometry Systems), and electronic compensation was performed with antibody capture beads (BD Biosciences). Data were analyzed using FlowJo version 9.9 (TreeStar)

Confocal microscopy-histocytometry. Immunohistochemistry was performed on 5 to $10 \mu \mathrm{m}$ tissue sections mounted on glass slides. $\mathrm{H} \& \mathrm{E}$ staining was performed at American Histolabs Inc. For confocal microscopy, tissue sections were deparaffinized and rehydrated with deionized water. Antigen retrieval was performed using Borg Decloaker RTU (Biocare Medical) in a decloaking chamber, with slides heated to $110^{\circ} \mathrm{C}$ for 15 minutes, or slides were treated with a proteinase $\mathrm{K}$ solution for 15 minutes for TUNEL staining according to the manufacturer's instructions (Click-IT Plus TUNEL Assay, Invitrogen, Thermo Fisher Scientific). Slides were then rinsed in PBS and permeabilized, and relevant primary antibodies were applied. A 2-hour incubation at room temperature followed. Slides were then washed in PBS, and corresponding Alexa Fluor dye-conjugated secondary antibodies were added for 2 hours at room temperature. Following incubation, slides were rinsed with $\mathrm{PBS}$ and stained with conjugated antibodies for 2 hours. Finally, JOJO-1 staining was applied, and slides were mounted for imaging. Confocal images were obtained on a Nikon C2si Confocal Running NIS-Elements AR with a $\times 40$ (NA 1.3) objective and analyzed using Imaris software, version 8.4 (Bitplane). Spectral spillover between optical detection channels was corrected through live spectral unmixing using data acquired from samples singly stained with the respective fluorochromes. Quantitative analysis was performed using histocytometry. Images for histocytometry were acquired at a $512 \times 512$ pixel density, and the method was applied as previously published $(40,41)$. In brief, 3D imaging data sets were segmented computationally after acquisition based on their nuclear staining signal, and average voxel intensities for all channels were generated in Imaris after isosurface generation. The extracted statistical data were then exported to Microsoft Excel, concatenated into a single commaseparated values format, and imported into FlowJo, version 10.3, for further analysis. Quantitative analysis was performed on individual follicles from $3 \mathrm{HIV}^{+}$participants before and after vaccination. Single sections were analyzed. For histocytometrical Tfh cell enumeration, follicular areas were projected on a 2D plot format using the program FlowJo and gated based on CD2O intensity (CD20 hi-dim) and Ki67. The same criteria were applied to all tissues. Follicular areas in regions displaying considerable tissue fragmentation or poorly resolved due to tissue folds or fat deposition that prevented accurate follicular mapping were not used in the analysis. The extent of FDC network area distribution $\left(\mathrm{mm}^{2}\right)$ was calculated using the program Imaris (BitPlane). Briefly, FDC stainings were segmented based on their mean intensity and FDC area mapping was performed by iso-surface generation. The analysis was performed for each follicle individually.

Real-time analysis by Fluidigm Biomark. Cryopreserved LN singlecell suspensions were thawed and rested in complete RPMI medium. Cells were labeled with monoclonal antibodies against CD3APCH7 (BD Biosciences) (clone SK7), CD4-Cy55PE (Life Technologies) (clone S3.5), CD27-PC5 (Beckman-Coulter) (clone 1A4CD27), CD45RO- ECD (Beckman-Coulter) (clone UCHL1), CD8 BV785 
(Biolegend) (clone SK1), TCRgd-FITC (BD Biosciences) (clone B1), CD56-FITC (BD Biosciences) (clone B159), CD19-PE (Biolegend) (clone HIB19), CD57- AF700 (Thermo Fisher Scientific) (clone NK1), CXCR5- PECy7 (eBioscience) (MU5UBEE), PD-1 BV711 (Biolegend) (clone EH12.2H7). Four-way sorting mode was used on FACS Aria II (BD Biosciences) to sort cell populations of interest. Twenty-five cells per subset were sorted in duplicate directly into 96-well microtiter plates containing CellsDirect One-Step PCR Buffer and pooled TaqMan gene expression assays $(2 \times$ CellsDirect Reaction Mix $5 \mu \mathrm{l}$, Superscript III + Taq polymerase $0.5 \mu 1,0.2 \times$ TaqMan primer pool 2.5 $\mu \mathrm{l}$, resuspension buffer $1 \mu \mathrm{l}$ ) (Thermo Fisher Scientific). After sorting, plates containing cells were immediately centrifuged $(1,000 \times g$ for 3 minutes) and kept on ice. Samples were subsequently transferred to PCR tubes and reverse transcription (RT) and target-specific preamplification were performed on a $\mathrm{C} 1000$ Thermal Cycler (Bio-Rad) as follows: $50^{\circ} \mathrm{C}$ for 20 minutes, $95^{\circ} \mathrm{C}$ for 2 minutes, $95^{\circ} \mathrm{C}$ for 15 seconds, $60^{\circ} \mathrm{C}$ for 4 minutes (last 2 steps repeated for 20 cycles). The resulting cDNA was diluted 1:1 with TE Buffer (10 mM Tris, 1 mM EDTA, $\mathrm{pH}$ 8.0) and stored at $-20^{\circ} \mathrm{C}$ until further analysis. Previously amplified samples were loaded onto 96.96 dynamic array IFC (Fluidigm) as previously described (79). The panel of TaqMan gene expression assays was qualified on human PBMCs and T lymphocytes as previously described (30-33, 75, 86). Expression threshold $(E t)$ values or $\log _{2}$ expression was used for all analysis and was determined using the following formula: $E t=40-C t$.

Statistics. Differences between groups were analyzed by Student's $t$ test (2-tailed), Mann-Whitney test, or 1-way ANOVA according to data distribution. Correlations between 2 variables were evaluated by Pearson's correlation and linear regression. Analyses were performed using GraphPad Prism (GraphPad Software Inc.). $P<0.05$ was considered significant, and results are presented as mean $\pm \mathrm{SD}$ unless otherwise indicated.

Study approval. All protocols of this study involving human samples were reviewed and approved by the University of Miami Institutional Review Board. Signed informed consent was obtained in accordance with the Declaration of Helsinki. Tonsillar tissue was acquired from anonymized discarded pathologic specimens from the Children's National Medical Center (CNMC) under the auspices of the
Basic Science Core of the District of Columbia Developmental Center for AIDS Research.

\section{Author contributions}

SP conceived the study. SP and CP designed the experiments. EM, SP, LRDA, LEG, DA, and VG performed and analyzed experiments. DH provided study samples. RP, DH, and RAK gave conceptual advice. EM, CP, and SP wrote the manuscript.

\section{Acknowledgments}

Authors would like to thank the personnel of the Tissue Analysis Core at the VRC, NIAID, NIH, for helpful discussions and suggestions; Dr M. Beddall, Immunotechnology Section, VRC, NIAID, $\mathrm{NIH}$, for help with antibody conjugations; and Brenda Hartman (VRC, NIAID, NIH) for expert assistance with graphics. Participant recruitment and sample collection were facilitated by the Clinical Sciences Core of the Miami Center for AIDS Research (Miami CFAR, P30AI073961) and the Clinical Research Center at the University of Miami. Core services and facilities of the Laboratory Sciences Core of the Miami CFAR and the Flow Cytometry Core of the Sylvester Comprehensive Cancer Center of the University of Miami were also utilized for sample processing and analyses. We also thank the study participants for their contribution to this study. This work was supported by NIH grants R56AI106718, R01 AI108472, AI123048, AI127347; and pilot grants from the University of Miami AIDS Institute (to SP). Research support was also provided by the Intramural Research Program of the VRC, NIAID, NIH, and a Collaboration for AIDS Vaccine Discovery grant (OP1032325) from the Bill and Melinda Gates Foundation (to RAK).

Address correspondence to: Constantinos Petrovas, Tissue Analysis Core, Immunology Laboratory, Vaccine Research Center, NIAID, NIH, 40 Convent Drive, Bldg. 40, Rm. 2615 MSC 3022, Bethesda, Maryland 20892, USA. Phone: 301.761.6993; Email: petrovas@mail.nih.gov. Or to: Savita Pahwa, University of Miami Miller School of Medicine, 1580 NW 10th Avenue, BCRI 712, Miami, Florida 33136, USA. Phone: 305.243.7732; Email: spahwa @med.miami.edu.
1. Antiretroviral Therapy Cohort Collaboration. Survival of HIV-positive patients starting antiretroviral therapy between 1996 and 2013: a collaborative analysis of cohort studies. Lancet HIV. 2017;4(8):e349-e356.

2. Crum-Cianflone NF, Wallace MR. Vaccination in HIV-infected adults. AIDS Patient Care STDS. 2014;28(8):397-410.

3. Grohskopf LA, et al. Prevention and control of seasonal influenza with vaccines: recommendations of the advisory committee on immunization practices-United States, 2017-18 influenza season. Am J Transplant. 2017;17(11):2970-2982.

4. Estes JD. Pathobiology of HIV/SIV-associated changes in secondary lymphoid tissues. Immunol Rev. 2013;254(1):65-77.

5. Pantaleo G, et al. Role of lymphoid organs in the pathogenesis of human immunodeficiency virus (HIV) infection. Immunol Rev. 1994;140:105-130.

6. Schacker TW, et al. Collagen deposition in HIV-1 infected lymphatic tissues and T cell homeostasis. J Clin Invest. 2002;110 (8):1133-1139.

7. Schacker TW, et al. Persistent abnormalities in lymphoid tissues of human immunodeficiency virus-infected patients successfully treated with highly active antiretroviral therapy. J Infect Dis. 2002;186(8):1092-1097.

8. Beck CR, et al. Influenza vaccination for immunocompromised patients: systematic review and meta-analysis from a public health policy perspective. PLoS One. 2011;6(12):e29249.

9. Fritz $S$, et al. Virosomal influenza-vaccine induced immunity in HIV-infected individuals with high versus low CD4+ T-cell counts: clues towards a rational vaccination strategy. AIDS. 2010;24(14):2287-2289.

10. Tebas P, et al. Poor immunogenicity of the H1N1 2009 vaccine in well controlled HIV-infected individuals. AIDS. 2010;24(14):2187-2192.

11. George VK, et al. HIV infection worsens age-asso- ciated defects in antibody responses to influenza vaccine. J Infect Dis. 2015;211(12):1959-1968.

12. Pallikkuth S, Pilakka Kanthikeel S, Silva SY, Fischl M, Pahwa R, Pahwa S. Upregulation of IL-21 receptor on $\mathrm{B}$ cells and IL-21 secretion distinguishes novel $2009 \mathrm{H} 1 \mathrm{~N} 1$ vaccine responders from nonresponders among HIV-infected persons on combination antiretroviral therapy. JImmunol. 2011;186(11):6173-6181.

13. Parmigiani A, et al. Impaired antibody response to influenza vaccine in HIV-infected and uninfected aging women is associated with immune activation and inflammation. PLoS One. 2013;8(11):e79816.

14. Breitfeld D, et al. Follicular B helper T cells express CXC chemokine receptor 5 , localize to $\mathrm{B}$ cell follicles, and support immunoglobulin production. JExp Med. 2000;192(11):1545-1552.

15. Schaerli P, Willimann K, Lang AB, Lipp M, Loetscher P, Moser B. CXC chemokine recep- 
tor 5 expression defines follicular homing $\mathrm{T}$ cells with B cell helper function. J Exp Med. 2000;192(11):1553-1562.

16. Chtanova $\mathrm{T}$, et al. $\mathrm{T}$ follicular helper cells express a distinctive transcriptional profile, reflecting their role as non-Th1/Th2 effector cells that provide help for B cells. J Immunol. 2004;173(1):68-78.

17. Fazilleau N, McHeyzer-Williams LJ, Rosen H, McHeyzer-Williams MG. The function of follicular helper T cells is regulated by the strength of $\mathrm{T}$ cell antigen receptor binding. Nat Immunol. 2009;10(4):375-384.

18. Havenith $\mathrm{SH}$, et al. $\mathrm{CXCR} 5^{+} \mathrm{CD} 4^{+}$follicular helper $\mathrm{T}$ cells accumulate in resting human lymph nodes and have superior B cell helper activity. Int Immunol. 2014;26(3):183-192.

19. Shulman Z, et al. Dynamic signaling by T follicular helper cells during germinal center B cell selection. Science. 2014;345(6200):1058-1062.

20. Bauquet AT, et al. The costimulatory molecule ICOS regulates the expression of c-Maf and IL-21 in the development of follicular T helper cells and TH-17 cells. Nat Immunol. 2009;10(2):167-175.

21. Bélanger S, Crotty S. Dances with cytokines, featuring TFH cells, IL-21, IL-4 and B cells. Nat Immunol. 2016;17(10):1135-1136.

22. Lindqvist M, et al. Expansion of HIV-specific T follicular helper cells in chronic HIV infection. JClin Invest. 2012;122(9):3271-3280.

23. Perreau M, et al. Follicular helper T cells serve as the major CD4 T cell compartment for HIV-1 infection, replication, and production. JExp Med. 2013;210(1):143-156.

24. Petrovas C, et al. CD4 T follicular helper cell dynamics during SIV infection. JClin Invest. 2012;122(9):3281-3294.

25. Boswell KL, et al. Loss of circulating CD4 T cells with B cell helper function during chronic HIV infection. PLoS Pathog. 2014;10(1):e1003853.

26. Pallikkuth S, et al. Impaired peripheral blood T-follicular helper cell function in HIV-infected nonresponders to the $2009 \mathrm{H} 1 \mathrm{~N} 1 / 09$ vaccine. Blood. 2012;120(5):985-993.

27. Crotty S. Follicular helper CD4 T cells (TFH). Annu Rev Immunol. 2011;29:621-663.

28. Kim JR, Lim HW, Kang SG, Hillsamer P, Kim CH. Human $\mathrm{CD} 7^{+}$germinal center-T cells are the major helpers for GC-B cells and induce class switch recombination. BMC Immunol. 2005;6:3.

29. Bentebibel SE, et al. Induction of ICOS ${ }^{+} \mathrm{CXCR}^{+}$ $\mathrm{CXCR5}^{+} \mathrm{TH}$ cells correlates with antibody responses to influenza vaccination. Sci Transl Med. 2013;5(176):176ra32.

30. Dong C, et al. ICOS co-stimulatory receptor is essential for T-cell activation and function. Nature. 2001;409(6816):97-101.

31. Velu V, et al. Induction of Th1-biased $\mathrm{T}$ follicular helper (Tfh) cells in lymphoid tissues during chronic simian immunodeficiency virus infection defines functionally distinct germinal center $\mathrm{Tfh}$ cells. J Immunol. 2016;197(5):1832-1842.

32. Yusuf I, et al. Germinal center $\mathrm{T}$ follicular helper cell IL-4 production is dependent on signaling lymphocytic activation molecule receptor (CD150). JImmunol. 2010;185(1):190-202.

33. Groom JR, et al. CXCR3 chemokine receptorligand interactions in the lymph node optimize $\mathrm{CD} 4^{+} \mathrm{T}$ helper 1 cell differentiation. Immunity.
2012;37(6):1091-1103.

34. Morita R, et al. Human blood CXCR5(+) CD4(+) T cells are counterparts of $\mathrm{T}$ follicular cells and contain specific subsets that differentially support antibody secretion. Immunity. 2011;34(1):108-121.

35. Zhang ZQ, et al. Reversibility of the pathological changes in the follicular dendritic cell network with treatment of HIV-1 infection. Proc Natl Acad Sci U S A.1999;96(9):5169-5172.

36. Victora GD, Dominguez-Sola D, Holmes AB, Deroubaix S, Dalla-Favera R, Nussenzweig MC. Identification of human germinal center light and dark zone cells and their relationship to human B-cell lymphomas. Blood. 2012;120(11):2240-2248.

37. Yamamoto T, et al. Quality and quantity of TFH cells are critical for broad antibody development in SHIVAD8 infection. Sci Transl Med. 2015;7(298):298ra120.

38. Vargas-Inchaustegui DA, et al. Vaccine induction of lymph node-resident Simian immunodeficiency virus Env-specific T follicular helper cells in rhesus macaques. Jimmunol. 2016;196(4):1700-1710.

39. Age-group Distribution of Influenza Positive Specimens Reported by Public Health Laboratories, National Summary, 2017-18 Influenza Season through the Week Ending May 26, 2018. Center for Disease Control and Prevention. https://gis.cdc.gov/grasp/fluview/flu_by_age_ virus.html. Accessed June 8, 2018.

40. Gerner MY, Kastenmuller W, Ifrim I, Kabat J, Germain RN. Histo-cytometry: a method for highly multiplex quantitative tissue imaging analysis applied to dendritic cell subset microanatomy in lymph nodes. Immunity. 2012;37(2):364-376.

41. Petrovas C, et al. Follicular CD8 T cells accumulate in HIV infection and can kill infected cells in vitro via bispecific antibodies. Sci Transl Med. 2017;9(373):eaag2285.

42. Amodio D, et al. Quantitative multiplexed imaging analysis reveals a strong association between immunogen-specific B cell responses and tonsillar germinal center immune dynamics in children after influenza vaccination. J Immunol. 2018;200(2):538-550.

43. Sato K, Honda SI, Shibuya A, Shibuya K. Improved protocol for the isolation of naive follicular dendritic cells. Mol Immunol. 2016;78:140-145.

44. Usui $\mathrm{K}$, et al. Isolation and characterization of naïve follicular dendritic cells. Mol Immunol. 2012;50(3):172-176

45. Palmer BE, Blyveis N, Fontenot AP, Wilson CC Functional and phenotypic characterization of $\mathrm{CD} 57^{+} \mathrm{CD} 4{ }^{+} \mathrm{T}$ cells and their association with HIV-1-induced T cell dysfunction. JImmunol. 2005;175(12):8415-8423.

46. Bouzahzah F, Bosseloir A, Heinen E, Simar LJ. Human germinal center $\mathrm{CD} 4^{+} \mathrm{CD} 57^{+} \mathrm{T}$ cells act differently on B cells than do classical T-helper cells. Dev Immunol. 1995;4(3):189-197.

47. Fernandez S, French MA, Price P. Immunosenescent $\mathrm{CD} 57^{+} \mathrm{CD} 4^{+} \mathrm{T}$-cells accumulate and contribute to interferon $\gamma$ responses in HIV patients responding stably to ART. Dis Markers. 2011;31(6):337-342.
48. Cannons JL, et al. Optimal germinal center responses require a multistage T cell:B cell adhesion process involving integrins, SLAMassociated protein, and CD84. Immunity. 2010;32(2):253-265.

49. Lal G, et al. IL-10 from marginal zone precursor B cells controls the differentiation of Th17, Tfh and Tfr cells in transplantation tolerance. Immunol Lett. 2016;170:52-63.

50. Tian Y, Mollo SB, Harrington LE, Zajac AJ. IL-10 Regulates memory T cell development and the balance between Th1 and follicular Th cell responses during an acute viral infection. J Immunol. 2016;197(4):1308-1321.

51. Acton SE, Reis e Sousa C. Dendritic cells in remodeling of lymph nodes during immune responses. Immunol Rev. 2016;271(1):221-229.

52. Wang X, et al. Follicular dendritic cells help establish follicle identity and promote B cell retention in germinal centers. JExp Med. 2011;208(12):2497-2510.

53. Park CS, Choi YS. How do follicular dendritic cells interact intimately with B cells in the germinal centre? Immunology. 2005;114(1):2-10.

54. Cremasco V, et al. B cell homeostasis and follicle confines are governed by fibroblastic reticular cells. Nat Immunol. 2014;15(10):973-981.

55. Estes JD, Haase AT, Schacker TW. The role of collagen deposition in depleting $\mathrm{CD} 4^{+} \mathrm{T}$ cells and limiting reconstitution in HIV-1 and SIV infections through damage to the secondary lymphoid organ niche. Semin Immunol. 2008;20(3):181-186.

56. Diaz A, et al. Factors associated with collagen deposition in lymphoid tissue in longterm treated HIV-infected patients. AIDS 2010;24(13):2029-2039.

57. Burton GF, Masuda A, Heath SL, Smith BA, Tew JG, Szakal AK. Follicular dendritic cells (FDC) in retroviral infection: host/pathogen perspectives. Immunol Rev. 1997;156:185-197.

58. Haase AT, et al. Quantitative image analysis of HIV-1 infection in lymphoid tissue. Science. 1996;274(5289):985-989.

59. Pantaleo G, et al. HIV infection is active and progressive in lymphoid tissue during the clinically latent stage of disease. Nature. 1993;362(6418):355-358.

60. Schmitz J, et al. Follicular dendritic cells retain HIV-1 particles on their plasma membrane, but are not productively infected in asymptomatic patients with follicular hyperplasia. J Immunol. 1994;153(3):1352-1359.

61. Tenner-Racz K, et al. The unenlarged lymph nodes of HIV-1-infected, asymptomatic patients with high CD4 $\mathrm{T}$ cell counts are sites for virus replication and $\mathrm{CD} 4 \mathrm{~T}$ cell proliferation. The impact of highly active antiretroviral therapy. JExp Med.1998;187(6):949-959.

62. Schacker TW, et al. Amount of lymphatic tissue fibrosis in HIV infection predicts magnitude of HAART-associated change in peripheral CD4 cell count. AIDS. 2005;19(18):2169-2171.

63. Cagigi A, Nilsson A, Pensieroso S, Chiodi F. Dysfunctional B-cell responses during HIV-1 infection: implication for influenza vaccination and highly active antiretroviral therapy. Lancet Infect Dis. 2010;10(7):499-503.

64. Malaspina A, et al. Compromised B cell responses 
to influenza vaccination in HIV-infected individuals. J Infect Dis. 2005;191(9):1442-1450.

65. Titanji K, et al. Loss of memory B cells impairs maintenance of long-term serologic memory during HIV-1 infection. Blood. 2006;108(5):1580-1587.

66. Heesters BA, et al. Follicular dendritic cells retain infectious HIV in cycling endosomes. PLoS Pathog. 2015;11(12):e1005285.

67. Tew JG, Mandel TE. Prolonged antigen half-life in the lymphoid follicles of specifically immunized mice. Immunology. 1979;37(1):69-76.

68. Banga R, et al. PD-1(+) and follicular helper T cells are responsible for persistent HIV-1 transcription in treated aviremic individuals. Nat Med. 2016;22(7):754-761.

69. Cubas RA, et al. Inadequate $\mathrm{T}$ follicular cell help impairs B cell immunity during HIV infection. Nat Med. 2013;19(4):494-499.

70. Pallikkuth S, et al. Impaired peripheral blood T-follicular helper cell function in HIV-infected nonresponders to the $2009 \mathrm{H1N1} / 09$ vaccine. Blood. 2012;120(5):985-993.

71. Rosenberg YJ, et al. Enhanced follicular dendritic cell function in lymph nodes of simian immunodeficiency virus-infected macaques: consequences for pathogenesis. Eur J Immunol. 1997;27(12):3214-3222.

72. Harker JA, Lewis GM, Mack L, Zuniga EI. Late interleukin-6 escalates $\mathrm{T}$ follicular helper cell responses and controls a chronic viral infection. Science. 2011;334(6057):825-829.

73. Wu Y, El Shikh ME, El Sayed RM, Best AM, Szakal AK, Tew JG. IL- 6 produced by immune complex-activated follicular dendritic cells promotes germinal center reactions, IgG responses and somatic hypermutation. Int Immunol. 2009;21(6):745-756.

74. Sanz I, Wei C, Lee FE, Anolik J. Phenotypic and functional heterogeneity of human memory $B$ cells. Semin Immunol. 2008;20(1):67-82.

75. Moir S, et al. Normalization of B cell counts and subpopulations after antiretroviral therapy in chronic HIV disease. J Infect Dis. 2008;197(4):572-579.

76. Gougeon ML, et al. Programmed cell death in peripheral lymphocytes from HIV-infected persons: increased susceptibility to apoptosis of CD4 and CD8 T cells correlates with lymphocyte activation and with disease progression. J Immunol. 1996;156(9):3509-3520.

77. Pauthner M, et al. Elicitation of robust tier 2 neutralizing antibody responses in nonhuman primates by HIV envelope trimer immunization using optimized approaches. Immunity. 2017;46(6):1073-1088.e6.

78. Havenar-Daughton C, et al. CXCL13 is a plasma biomarker of germinal center activity. Proc Natl Acad Sci U S A . 2016;113(10):2702-2707.

79. de Armas LR, et al. Induction of IL21 in periph- eral $\mathrm{T}$ follicular helper cells is an indicator of influenza vaccine response in a previously vaccinated HIV-infected pediatric cohort. JImmunol. 2017;198(5):1995-2005.

80. Pilkinton MA, et al. Greater activation of peripheral $\mathrm{T}$ follicular helper cells following high dose influenza vaccine in older adults forecasts seroconversion. Vaccine. 2017;35(2):329-336.

81. Locci M, et al. Human circulating PD- $1^{+} \mathrm{CXCR} 3$ CXCR $5^{+}$memory Th cells are highly functional and correlate with broadly neutralizing HIV antibody responses. Immunity. 2013;39(4):758-769.

82. Kroon FP, van Dissel JT, de Jong JC, Zwinderman K, van Furth R. Antibody response after influenza vaccination in HIV-infected individuals: a consecutive 3-year study. Vaccine. 2000;18(26):3040-3049.

83. Koutsakos M, et al. Circulating TFH cells, serological memory, and tissue compartmentalization shape human influenza-specific B cell immunity. Sci Transl Med. 2018;10(428):eaan8405.

84. Hale JS, Ahmed R. Memory T follicular helper CD4 T cells. Front Immunol. 2015;6:16.

85. Hale JS, et al. Distinct memory CD4 ${ }^{+} \mathrm{T}$-cells with commitment to $\mathrm{T}$ follicular helper- and $\mathrm{T}$ helper 1 cell lineages are generated after acute viral infection. Immunity. 2013;38(4):805-817.

86. Dominguez MH, et al. Highly multiplexed quantitation of gene expression on single cells. JImmunol Methods. 2013;391(1-2):133-145. 